
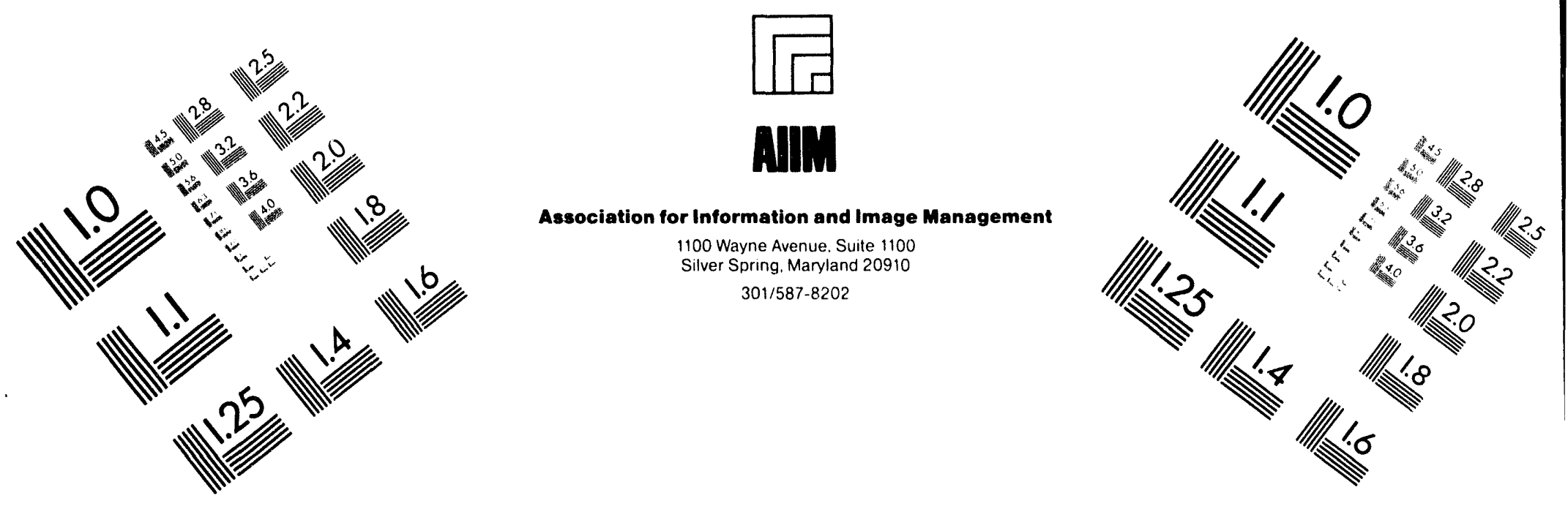

\title{
Centimeter
}

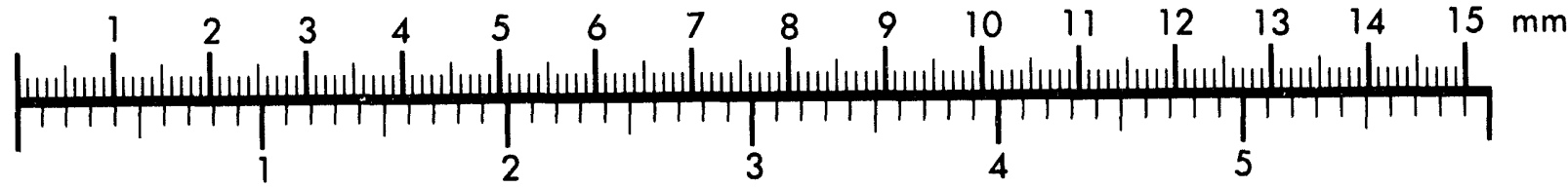
Inches
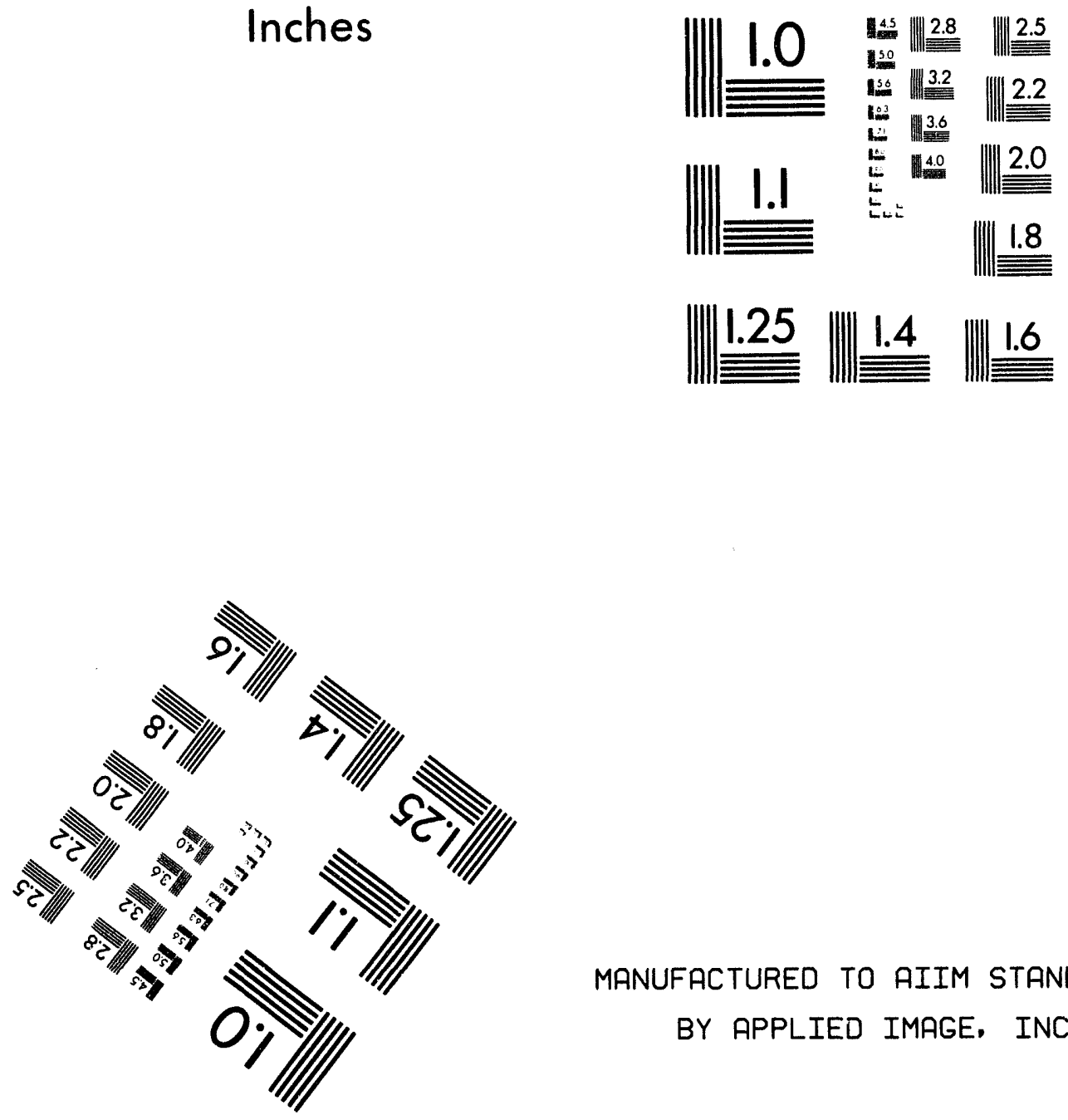

MANUFACTURED TO AIIM STANDARDS

BY APPLIED IMAGE, INC.

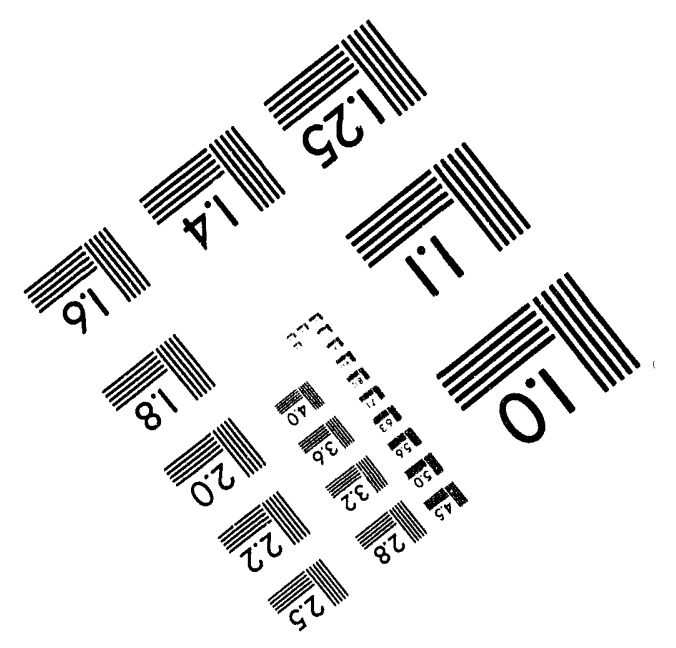



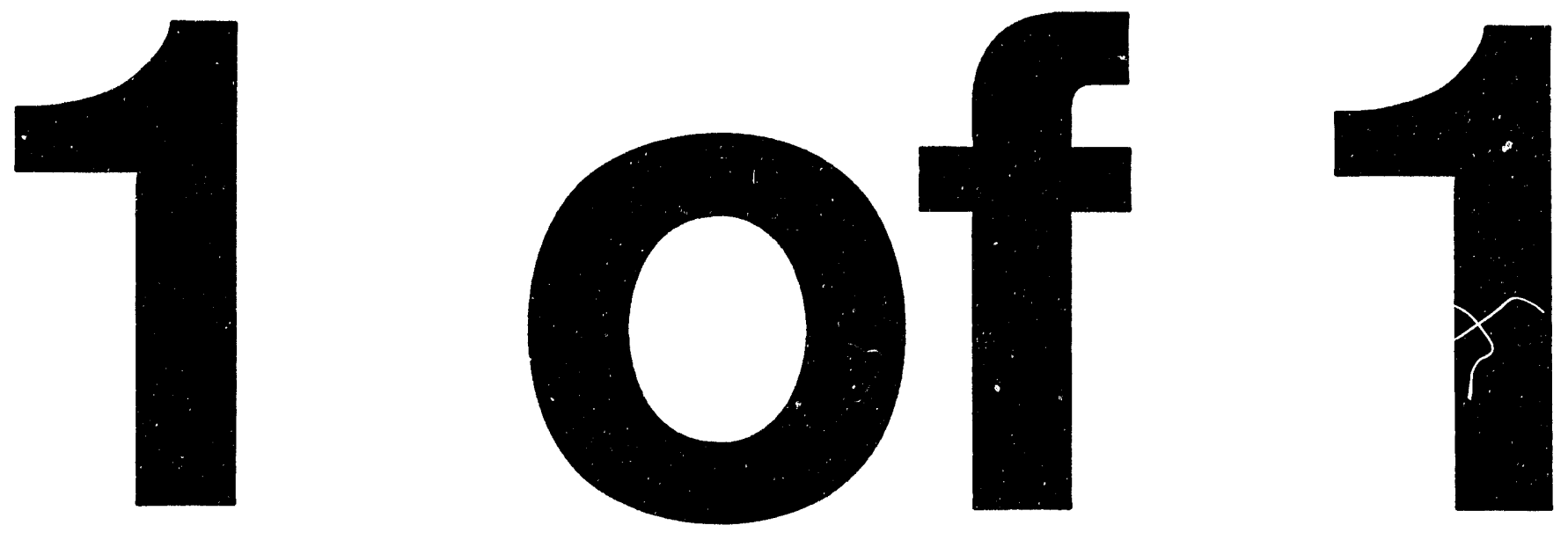


\section{Detonability of DMSO/LX-10-1 and DMSO/PBX-9404 Solutions}

\section{INTRODUCTION}

Although Lawrence Livermore National Laboratory has been involved in weapons disassembly since its involvement in weapons design, the Lab was recently requested by the Department of Energy to extend its responsibility for LLNL-designed weapons to include dismantlement of some systems in the cold war arsenal. ${ }^{1,2}$ Dissolution of LX-10-1 and PBX-9404 explosive from two artillery fired atomic projectiles (AFAPs) can be accomplished using dimethyl sulfoxide. The compositions of LX-10-1 and PBX-9404 are given in Table 1. We have evaluated the detonability of solutions of these two plastic bonded explosives in dimethyl sulfoxide (DMSO) under shock and thermal scenarios based on the UN "Recommendations on the Transport of Dangerous Goods - Tests and Criteria" (ST/SG/AC. 10/11) ${ }^{3}$ and US Army Technical Bulletin 700-2. ${ }^{4}$ Prior to the relatively large scale shock and thermal sensitivity testing, small scale safety tests and thermochemical code calculations were used as a preliminary estimate of the detonability and hazards associated with up to $33 \%$ of these explosives in DMSO. Thermochemical calculations, small scale safety testing, and gap testing all indicate that these solutions are not detonable. We are currently in the process of evaluating these solutions using the small scale cookoff bomb (SCB) test.

Table 1. Compositions of LX-10-1 and PBX-9404.

\begin{tabular}{lll}
\hline Composition & PBX-9404 & LX-10-1 \\
\hline HMX & 94 & 94.5 \\
NC & 3 & \\
CEF & 3 & \\
Viton A & & 5.5 \\
\hline
\end{tabular}

\section{PRELIMINARY TESTING}

Preliminary evaluation of these materials was accomplished using small scale safety testing techniques and thermochemical code calculations. The DOE Explosives Safety Manual $^{5}$ allows up to $33 \%$ explosive sol to be handled as a non explosive for laboratory use and up to $25 \%$ solutions can be stored as a non explosive. Whenever new explosive mixtures are made, it is LLNLs policy to evaluate their handlability using a series of 5 small scale tests. 6 Of these tests, only friction sensitivity is not run on liquid samples. A general overview of small scale testing and the caveats associated with the various tests can be found in reference 7 . 


\section{Small Scale Safety Testing}

Drop Hammer tests: ${ }^{8}$ The drop hammer offers a means of evaluating impact sensitivity by dropping a $2.5 \mathrm{~kg}$ weight from a variable height onto a small sample of explosive (generally about $35 \mathrm{mg}$ ). The criterion for "explosion" is an arbitrary level of sound produced by the explosive on impact. The distance in centimeters required to achieve this "explosion" is determined by the Bruceton statistical method using 10 drops of varying height. If the sample fails to explode, the result is shown by $a>177 \mathrm{~cm}$ value (the maximum height of the drop tower). Values for LX-10-1, PBX-9404, and their 33\% solutions are given in Table 2. Note, drop heights for solids and liquids should not be compared directly since initiating mechanisms differ, but clearly these liquids are not impact sensitive as measured by this test.

Chemical Reactivity Test (CRT): ${ }^{9}$ The LLNL CRT test analyzes selected gasses known to be decomposition products of a variety of common nitramine explosives. The test is generally run on $0.25 \mathrm{~g}$ of sample for $22 \mathrm{~h}$ at $120^{\circ} \mathrm{C}$. If a one gram sample generates more than $2 \mathrm{cc}$ of gas (all species analyzed), it is considered suspect and generally receives further evaluation at 100 or $80^{\circ} \mathrm{C}$. One cc of gas $/ \mathrm{g}$ of sample is approximately $0.1-0.2 \%$ decomposition of the explosive ingredients. Values of LX-10-1, PBX-9404, and their $33 \%$ solutions are given in Table 2 .

Differential Scanning Calorimetry (DSC): 10,11 The onset of the explosive decomposition exotherm has been used by LLNL and other explosives laboratories as an indication of the thermal stability of explosive materials. For explosives which exhibit global rate constants, the DSC exotherm can be fitted to the Frank-Kamenetskii relationship to predict decomposition temperatures of larger quantities of the material. Values of the DSC onset temperatures for LX-10-1, PBX-9404, and their $33 \%$ solutions are given in Table 2. The DSC traces for these materials are shown in Figures 1-4. DSC data from the solutions shows vaporization of the DMSO at $\sim 180^{\circ} \mathrm{C}$ followed by the $\mathrm{HMX}$ thermal decomposition exotherm. PBX-9404 decomposition is accelerated by the presence of Nitrocellulose (NC) and chloroethyl phosphate (CEF). This acceleration is dependent on the heating rate and is not appreciable in the DSC traces. The insert in the PBX-9404 trace shows the decomposition of the NC, The insert in the LX-10 trace shows the crystalcrystal transition of HMX with temperature. The acceleration has not observed in the $33 \%$ solutions of PBX-9404 or in the recrystallized material tested to date.

Electrostatic discharge (Spark) tests: ${ }^{12}$ The LLNL spark sensitivity test is a point to plane geometry version of the approaching electrode ESD test developed by the US Army at Picatinny Arsenal. In this test 1 Joule of energy is input into a sample $(-20 \mathrm{mg})$ of explosive through a $500 \Omega$ resistance to simulate static discharges from personnel. Usually the sample is contained in a ring situated on top of a mild steel cylinder $0.75^{\prime \prime}$ in diameter $x 0.3$ " high and covered with 2 mil mylar tape to prevent premature discharge. Table 2 shows that both liquids and both solid explosives are not sensitive to spark in this test. 
The small scale test results show clearly that there are no unexpected explosive hazards associated with the handling of $25-33 \%$ solutions of these HMX based explosives.

Table 2. Small Scale Safety testing of LX-10-1, PBX-9404 and their solutions in DMSO.

\begin{tabular}{lllll}
\hline Sample & 9404 & + DMSO & LX-10-1 & + DMSO \\
\hline DH(50) cm & $33 \mathrm{~cm}$ & $>177 \mathrm{~cm}$ & $44 \mathrm{~cm}$ & $>177 \mathrm{~cm}$ \\
CRT cc/.25g & 0.36 & 0.56 & 0.04 & 0.49 \\
DSC T(onset) C & $180^{\circ} \mathrm{C}$ & $262^{\circ} \mathrm{C}$ & $250^{\circ} \mathrm{C}$ & $270^{\circ} \mathrm{C}$ \\
Spark & Not sen & Not sen & Not sen & Not sen \\
\hline
\end{tabular}

\section{Thermochemical Calculations}

The TIGER thermochemical code ${ }^{13}$ has been used at LLNL for a number of years to predict the Chapman-Jougeut characteristics of detonating explosives. Because of the uncertainty in the gap tests as proposed in the UN procedures and the relatively large quantities required $(520 \mathrm{~g})$, this code was used to evaluate the 25/75:HE/DMSO solutions at two densities $(1.23 \mathrm{~g} / \mathrm{cc}$ and $1.4 \mathrm{~g} / \mathrm{cc})$. The results were similar and only the 1.23 calculations are presented in Table 3 . Here $\mathrm{P}, \mathrm{T}$, and $\mathrm{H}_{\mathrm{r}}$ are $\mathrm{C}$-J pressure, temperature and heat of reaction, respectively. $\Gamma$ is a constant which is close to 3 for ideal explosives. $\mathrm{V}(\mathrm{d}), \mathrm{V}(\mathrm{p})$ and $\mathrm{V}(\mathrm{s})$ are predicted detonation, particle and sound velocity, respectively.

Table 3. Tiger calculations for 25/75:HMX/DMSO C-J conditions and decomposition products.

\begin{tabular}{cccccccc}
\hline $\begin{array}{c}\text { CJ Value } \\
\text { (units) }\end{array}$ & $\mathrm{P}$ & $\mathrm{T}$ & $\mathrm{H}_{\mathrm{r}}$ & $\Gamma$ & $\mathrm{V}(\mathrm{d})$ & $\mathrm{V}(\mathrm{p})$ & $\mathrm{V}(\mathrm{s})$ \\
& $(\mathrm{ATM})$ & $\left({ }^{\circ} \mathrm{K}\right)$ & $\mathrm{cal} / \mathrm{g}$ & & $(\mathrm{mm} / \mu \mathrm{s})$ & $(\mathrm{mm} / \mu \mathrm{s})$ & $(\mathrm{mm} / \mu \mathrm{s})$ \\
& $1.04 \mathrm{E} 5$ & 1515 & 1769 & 2.6 & 5.56 & 1.54 & 4.02 \\
\hline
\end{tabular}

Tiger calculations for decomposition products.

\begin{tabular}{cccccccc}
\hline Decomposition product & $\mathrm{H}_{2} \mathrm{O}$ & $\mathrm{CH}_{4}$ & $\mathrm{CO}_{2}$ & $\mathrm{~N}_{2}$ & $\mathrm{NH}_{3}$ & $\mathrm{~S}_{8}$ & $\mathrm{HCOOH}$ \\
mol/kg HE & 11.2 & 8.0 & 2.1 & 2.1 & 2.6 & 1.1 & 0.4 \\
phase & $\mathrm{g}$ & $\mathrm{g}$ & $\mathrm{g}$ & $\mathrm{g}$ & $\mathrm{g}$ & $\mathrm{g}$ & $\mathrm{g}$ \\
\hline Decomposition product & $\mathrm{H}_{2}$ & $\mathrm{CO}$ & $\mathrm{SO}_{2}$ & $\mathrm{C}$ & $\mathrm{H}_{2} \mathrm{SO}_{4}$ & & \\
mol/kg HE & 0.1 & .04 & .0003 & 12.0 & 0 & & \\
phase & $\mathrm{g}$ & $\mathrm{g}$ & $\mathrm{g}$ & $\mathrm{s}$ & $\mathrm{l}$ & & \\
\hline
\end{tabular}

Predicted detonation velocity $(5.56 \mathrm{~mm} / \mu \mathrm{s})$ is relatively low and C-J temperatures above $1800^{\circ} \mathrm{K}$ are typically required to sustain detonation. ${ }^{14}$ The conclusion is that these solutions are unlikely to detonate high order. Also of note is the large volume of carbon 
solid and ammonia predicted in the constituents of decomposition. This implies soot and reactive gasses might be present in the tank after gap testing is complete.

\section{GAP TESTS}

A variation of the NOL Card Gap Test ${ }^{15.16}$ (without cards) is used to evaluate detonability in the United Nations "Recommendations on the Transport of Dangerous Goods - Tests and Criteria". Figure 5 shows the test configuration for liquids. A detailed description of the test configuration and various safety features implemented in the $1-\mathrm{Kg}$ tank in the HEAF facility are given in Peer review \# 891 attached as Appendix A. Four sets of three tests each were run as follows: $25 \%$ PBX-9404 and 25\% LX-10-1 solutions at ambient; and 25\% PBX-9404 and 25\% LX-10-1 frozen solutions. Three criterion for failure to detonate are given: 1 . no hole in the witness plate; 2 . incomplete fragmentation of the cold rolled steel (CRS) tube; and 3. detonation velocity sound speed. In only one of all 12 tests had a crack propagated the complete length of the CRS tube. The witness plates were only slightly bent and the velocity probe measurements decayed to $1 \mathrm{~mm} / \mu \mathrm{s}$ in the ambient tests and zero in the frozen solid tests. A detailed discussion of each set of tests is given below.

In the ambient series of tests with both PBX-9404 and LX-10-1 solutions, the flow rate of $1.2 \mathrm{l} / \mathrm{min}$ was maintained with a floating ball flow meter. The volume of bubbling air was estimated by stopping air flow. Between 35 and $50 \mathrm{cc}$ 's of air were in the cylinder at the required flow rate ( $8-15 \%$ of the total volume of material). Vinyl tubing could not be used since it is soluble in DMSO and Teflon tubing was substituted. Figure 6 shows the postmortem photos of the PBX-9404/DMSO:25/75 tests at ambient. The steel witness plates were bent and thrown around in the firing tank but no holes or even indentations were observed of the diameter of the gap test cylinder. Test $\# 2$ in the figure shows the only example of a crack which propagated the complete length of the tube. The end of the tube adjacent to the pentalite booster was destroyed by the $240 \mathrm{Kbar}$ shock of the booster. The larger fragments from the middle of the cylinder indicate that the shock wave is dying out. These results are verified by the velocity probe results. Figure 8 shows the shock wave position with time from PBX-9404 run \#2 (the completely cracked tube). Timing begins (positive values) immediately after initiatiun of the detonator. The limiting velocity was about $1 \mathrm{~mm} / \mu \mathrm{s}$, clearly indicating that the fracture was not due to detonation. Table 4 shows the results from each test.

Postmortem photos of ambient LX-10-1/DMSO:25/75 gap tests are shown in Figure 7. The results were very similar to those from PBX-9404. Limiting velocity was again about $1 \mathrm{~mm} / \mu$ s (from data in Figure 9). Although there is some scatter at early time, it is clear that the booster overdriven early time velocities decay to reasonably constant velocities substantially below the predicted detonation velocities. Sound speeds of heterogeneous mixtures can be approximated by rule of mixtures. Estimates of the volume of air in the bubbling liquids was $10-15 \%$ and one test on pure DMSO gave velocities of $1.6 \mathrm{~mm} / \mu \mathrm{s}$ (see Fig. 10). Clearly a stable detonation wave has not formed 
under these test conditions. This implies that these materials are not shock initiating, i.e. no evidence of detonation in the material was observed.

Because DMSO freezes at $18.45^{\circ} \mathrm{C}\left(65.2^{\circ} \mathrm{F}\right)$, concern about the solutions freezing during transport and whether the segregation of HMX would sensitize the frozen material were addressed by gap tests on frozen material. DMSO has a tendency to supercool so dry ice was used to freeze the solutions. Figure 11 shows the setup and testing of the low temperature experiments. In Fig. 11a the dry ice container surrounding the test cylinder is shown. The lower section, which has no dry ice, is the wooden support for the detonator and booster. The mixtures of explosive and DMSO froze from the edge of the cylinder inward. Because of the volume change during crystallization, voids were created in the center and more solution was added (see Fig 11b) until the cylinder was completely full. The cylinders took approximately 30 minutes to freeze. This photo also shows the position of the thermocouple used to record the temperature at shot time and the wooden support for the velocity probe used to insure good electrical connections and prevent movement of the probe during removal of the dry ice prior to firing. The resistance of the probe is temperature dependent (122 $\Omega$ at ambient and $105 \Omega$ cold) and these values were used in estimating the velocity, Figure $1 \mathrm{lc}$ shows the firing tank shortly after firing. The cylinder, connecting wires, liquid, wooden residue from the booster/detonator support structure and some of the shielding to protect the tank are clearly visible. Figure 11d shows the recovered cylinder and witness plate.

Figure 12 shows the postmortem results of the frozen PBX-9404/DMSO:25/75 tests. In test \#7 a significant portion of the velocity probe was recovered intact. Figure 14 shows the position-time data from the velocity probe from test \#7. Within about 150 $\mu$ s after the detonator fired, the voltage dropped to a nearly constant value. There is then a discontinuity and the voltage decreases rapidly by about $1 \mathrm{~V}$ (corresponding to a short at the top of the cylinder) and remains constant thereafter for approximately $200 \mu \mathrm{s}$. When the shock wave reaches the top of the tube, the probe is disconnected from the cylinder resulting in the voltage going off scale. It would appear that the energy in the shock wave has been attenuated to the point that it will no longer crush the velocity probe after about $150 \mu \mathrm{s}$. Why the probe shorts at this time is currently unclear. A constant voltage is recorded until, after $\sim 350 \mu$ s, the weak shock has passed the end of the gap tube.

In the frozen LX-10-1/DMSO:25/75 tests (see Figure 13) results were similar to those from PBX-9404/DMSO. The velocity probes again showed (Fig. 15) a discontinuity in position (corresponding to rapid voltage jump) $200 \mu \mathrm{s}$ after the detonator was fired and transition to constant voltage corresponding to a short at the top of the cylinder. Because of concerns that the shock velocity in the steel wall was causing this discontinuity, the probe was moved 3/16" away from the wall in this shot with no difference in results. Although there are several questions about the probe behavior which are as yet unanswered, it is clear that none of the tests show propagation of the detonation wave through the PBX/DMSO solutions. 
Table 4. Firing Tank Test Parameters for Gap Tests.

\begin{tabular}{ccccccc}
\hline Test ID \# & Temp & $\Delta \mathrm{T}$ & $\Delta \mathrm{P}$ & $\mathrm{V}(\mathrm{l})$ & Hole in Plate & Fragments \\
\hline PBX-9404 & $\left({ }^{\circ} \mathrm{C}\right)$ & $\left({ }^{\circ} \mathrm{C}\right)$ & $(\mathrm{psi})$ & $(\mathrm{mm} / \mu \mathrm{s})$ & & \\
$1(542)$ & 18 & 37.8 & 28 & .95 & none & 2 \\
$2(543)$ & 18 & 55.0 & 24 & .97 & none & 2 \\
$3(544)$ & 18 & 46.1 & 24 & 1.02 & none & 2 \\
LX-10-1 & & & & & & \\
$4(545)$ & 18 & 48.8 & 23 & 1.11 & none & 11 \\
$5(547)$ & 18 & 58.3 & 24 & 1.05 & none & 5 \\
$6(551)$ & 18 & 68.3 & 22 & 1.06 & none & 7 \\
PBX-9404 & & & & & & \\
$7(552)$ & -11.3 & 40.5 & 20 & $\rightarrow 0$ & nore & 13 \\
$8(554)$ & -17.0 & 52.7 & 19 & $\rightarrow 0$ & none & 14 \\
$9(555)$ & -14.9 & 53.3 & 19 & $\rightarrow 0$ & none & 9 \\
LX-10-1 & & & & & & \\
$10(553)$ & -12.1 & 47.2 & 20 & 1.0 & none & 10 \\
$11(556)$ & -17.7 & 40.5 & 24 & 0.82 & none & 8 \\
$12(557)$ & -32.1 & 57.8 & 25 & $\rightarrow 0$ & none & 12 \\
DMSO only & & & & & & 6 \\
$13(558)$ & 18 & 53.3 & 21 & 1.6 & none & 6 \\
\hline
\end{tabular}

\section{CONCLUSIONS}

The results of small scale safety and zero-card gap tests on $25 \%$ solutions of two explosives (PBX-9404 and LX-10-1) in dimethyl sulfoxide (DMSO) indicate that these solutions are not detonable by shock. Tests by other workers on mixtures of HMX in solutions, ${ }^{17}$ suspensions, ${ }^{18}$ and solids ${ }^{19}$ indicate that a cutoff concentration where the overdriven explosive will no longer support detonation is expected. Our results are consistent with these, and indeed fall into the $25-33 \%$ regime identified by the DOE Explosives Safety Manual. The thermochemical code result were consistent with observations. In no case, in neither the solutions nor frozen solids, was any evidence of sustained detonation observed. Some caveats regarding this assessment and comments on the testing are in order. The gap test is limited because of its small failure diameter ( 3.65 $\mathrm{cm}$ ). These solutions of DMSO/PBX-9404 or DMSO/LX-10-1 will eventually be shipped to a waste treatment facility or be recycled to recover the solvent and explosive. The shipping containers of choice are 40-55 gallon drums whose diameter will clearly be much larger. Fortunately, the low C-J temperature calculated from TIGER implies large failure diameter detonability is unlikely.

A second area of concern is the frozen solutions. Although an attempt was made to emulate a reasonable handling scenario in these tests, it may be possible to preferentially crystallize the HMX and allow it to settle out. When $25-35 \%$ suspensions of fuel oil/HMX were allowed to settle and higher concentrations of HMX formed at the bottom 
of the tube in similar tests, these materials did show evidence of detonation. Although it appears unlikely that this would happen with DMSO/explosive solutions, it is recommended that reasonable effort be taken to prevent the solutions from freezing wherever possible.

Finally, as is well known, DMSO can carry dissolved chemicals across the skin membrane into the body. The effect of HMX and other components when administered in this manner is not known. Responsible handling of these chemicals is required at all times. Decomposition products from the firing tank are currently being evaluated for mutagenicity. Strong odor of oxides of sulfur and possibly ammonia were observed after each test and full protective gear was used during cleanup operations. With proper attention to detail, it should be possible to handle these materials as non-explosives.

\section{ACKNOWLEDGMENTS}

The authors gratefully acknowledge both financial and $\mathrm{engineering} \mathrm{support} \mathrm{from}$ DTED especially P. D. Wapman and M. S. Nakano. L. Green performed and assisted with the interpretation of the TIGER thermochemical calculations. None of the tests would have been possible without the assistance of $\mathrm{L}$. Crouch and the crew of the $1 \mathrm{Kg}$ tank. Finally, R. Swansiger prepared the DMSO/explosive solutions and R. Garza assisted in the test setup.

\section{REFERENCES}

1. Energy and Technology Review, "Dismantling the Cold War Arsenal", UCRL-5000093-11 (November 1993) Lawrence Livermore National Laboratory, Livermore, CA.

2. C.O. Pruneda, A.R. Mitchell, and J.R. Humphrey, "Reusing the High Explosives from Dismantled Nuclear Weapons", UCRL-ID-116755 (March 1994) Lawrence Livermore National Laboratory, Livermore, CA

3. Transport of Dangerous Goods - NATO Test Manual, ST/SG/AG.10/11, United Nations (1986)

4. US Army Technical Bullinin TB-700-2, "Department of Defense Explosives Hazard Classification Procedures" (December 1989).

5. DOE Explosives Safety Manual, US Department of Energy, Asst. Sec. for Environment, Safety and Health, Office of Quality Programs, Rev. 6 (Oct. 1991).

6. Defense Systems/Nuclear Design Directorate, Facility Safety Procedure, High Explosives Application Facility, Building 191 (June 1993) Lawrence Livermore National Laboratory, Livermore, CA. 
7. A.M. Mellor, T.L. Boggs, J. Covino, C.W. Dickenson, D. Dreitzler, L.B. Thorn, R.B. Frey, P.W. Gibson, W.E. Roe, M. Kirshenbaum and D.M. Mann, Prog. Energy Combust. Sci., 14, 213, (1988)

8. B.M. Dobratz, LLNL Explosives Handbook, (March 16, 1981) UCRL-52997 (March 1981) Lawrence Livermore National Laboratory, Livermore, CA..

9. J.W. Frazer and K. Ernst, Exploive Stoffe 12A, (1964)

10. R.N. Rogers, Thermochim. Acta, 11, 131 (1975)

11. J. Zinn and R.N. Rogers, J. Phys. Chem., 66, 2645 (1962).

12. M. Kirshenbaum, US Army Tech Report 4955, Picatinny Arsenal, Dover, NJ. (1976)

13. M. Cowperthwaite and W.H. Zwisler, "Tiger Computer Program Documentation", SRI Pub No. Z106 (1973).

14. J. Kury, H.C. Hornig, E.LO. Lee, I.L. McDonnel, D.L. Ornellas, M. Finger, F.M. Strange, M.L. Wilkins, "Metal Acceleration by Chemical Explosives", Proc. 4th Symp. on Detonation, Oct. 12-15, 1965, US Naval Ordnance Laboratory, White Oak, MD.

15. R.W.Slape, MHSMP-84-22 Rev1, "The Material Qualification Test Discription and Criterion", (June 1984), Mason and Hanger - Silas Mason Co., Inc. Pantex Plant, Amarillo, TX.

16. J. Ribovich, R.W. Watson and F.C. Gibson, AIAA J. $\underline{6}, 1260$ (1968).

17. F.L. Simpson, F.H. Helm, P.C. Crawford and J.W. Kury, Proc 9th Synıp. (International) on Detonation, pp. 25 -38 (1989) US Naval Ordnance Laboratory, White Oak MD.

18. M.E. Lackey, "Testing to Determine Chemical Stability, Handling Characteristics, and Reactivity of Energetic-Fuel Mixtures" Rept. No. AMXTH-TE-CR-87132, Oak Ridge National Laboratory, Oak Ridge, TN, Apr 1988.

19. M.S. Kirshenbaum, "Reactivity of Explosives/Sediment Mixtures", Tech. Rept. ARLCD-TR-82007, US Army ARDCOM, May 1982, Dover, NJ. 


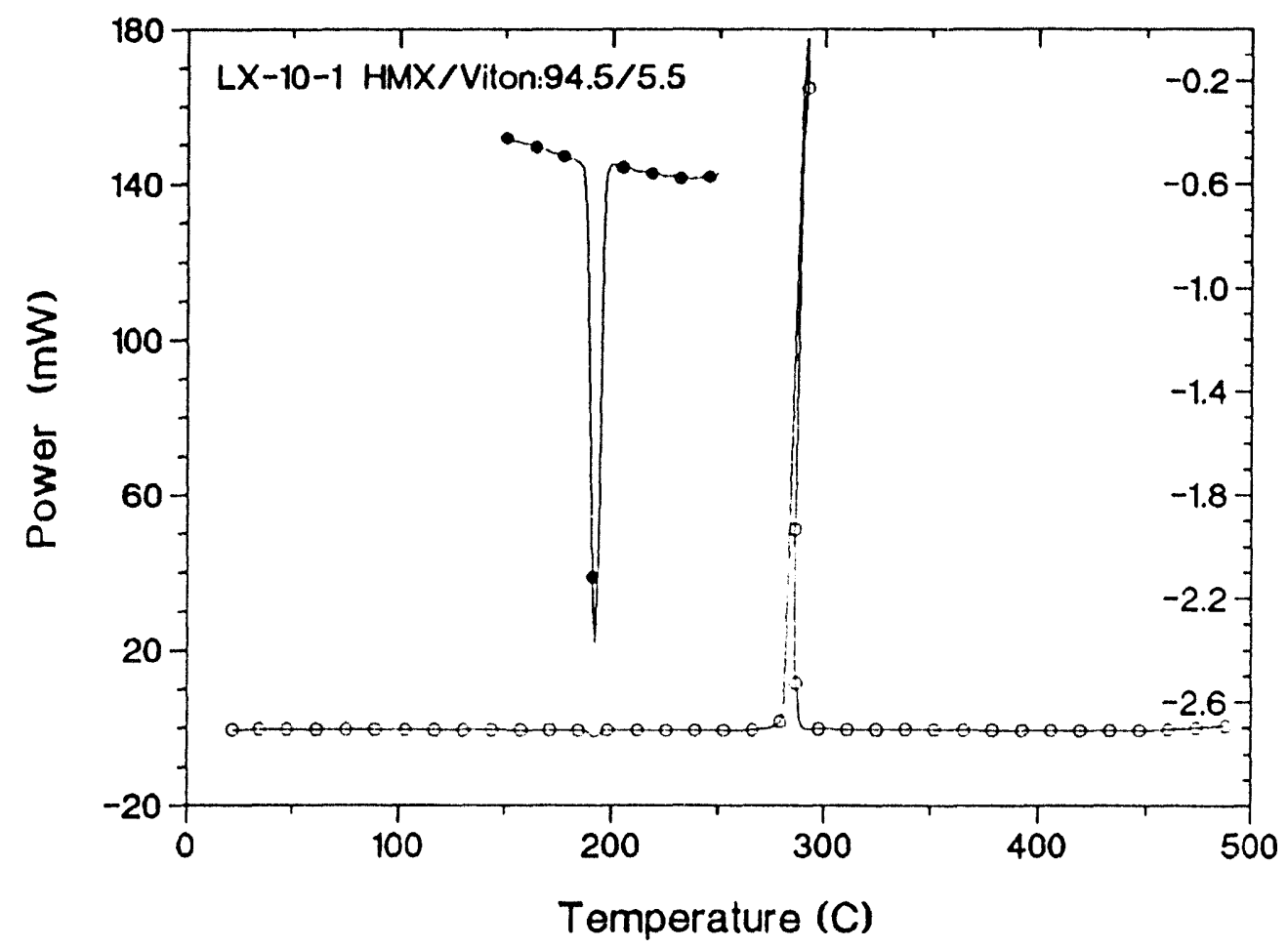

Figure 1. DSC trace of LX-10-1 (insert shows expanded view of HMX phase change).

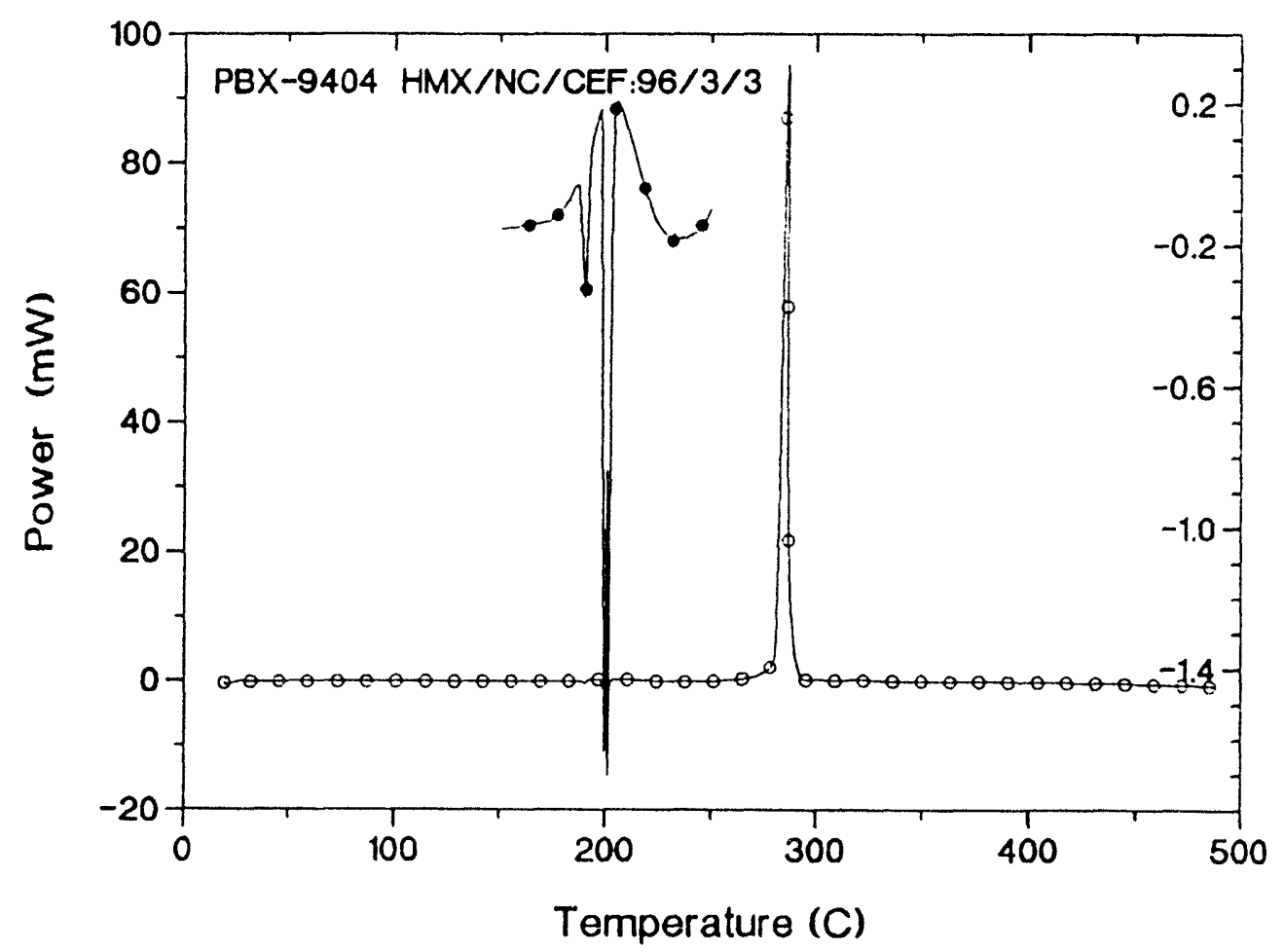

Figure 2. DSC trace of PBX-9404 (insert shows NC decomposition and phase change). 


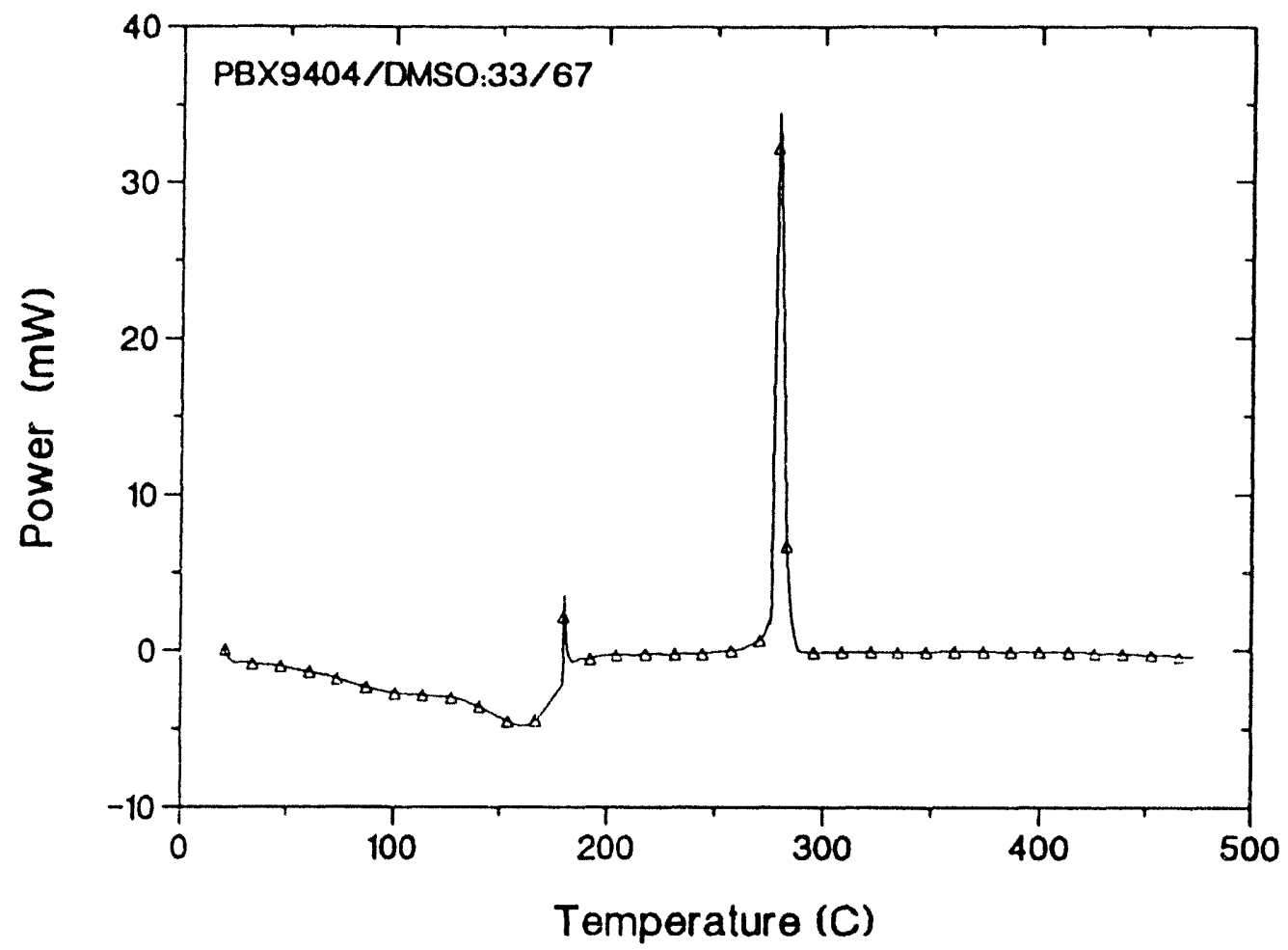

Figure 3. DSC trace of solution of 33/67:PBX-9404/DMSO shows vaporization of DMSO and exothermic decomposition of HMX.

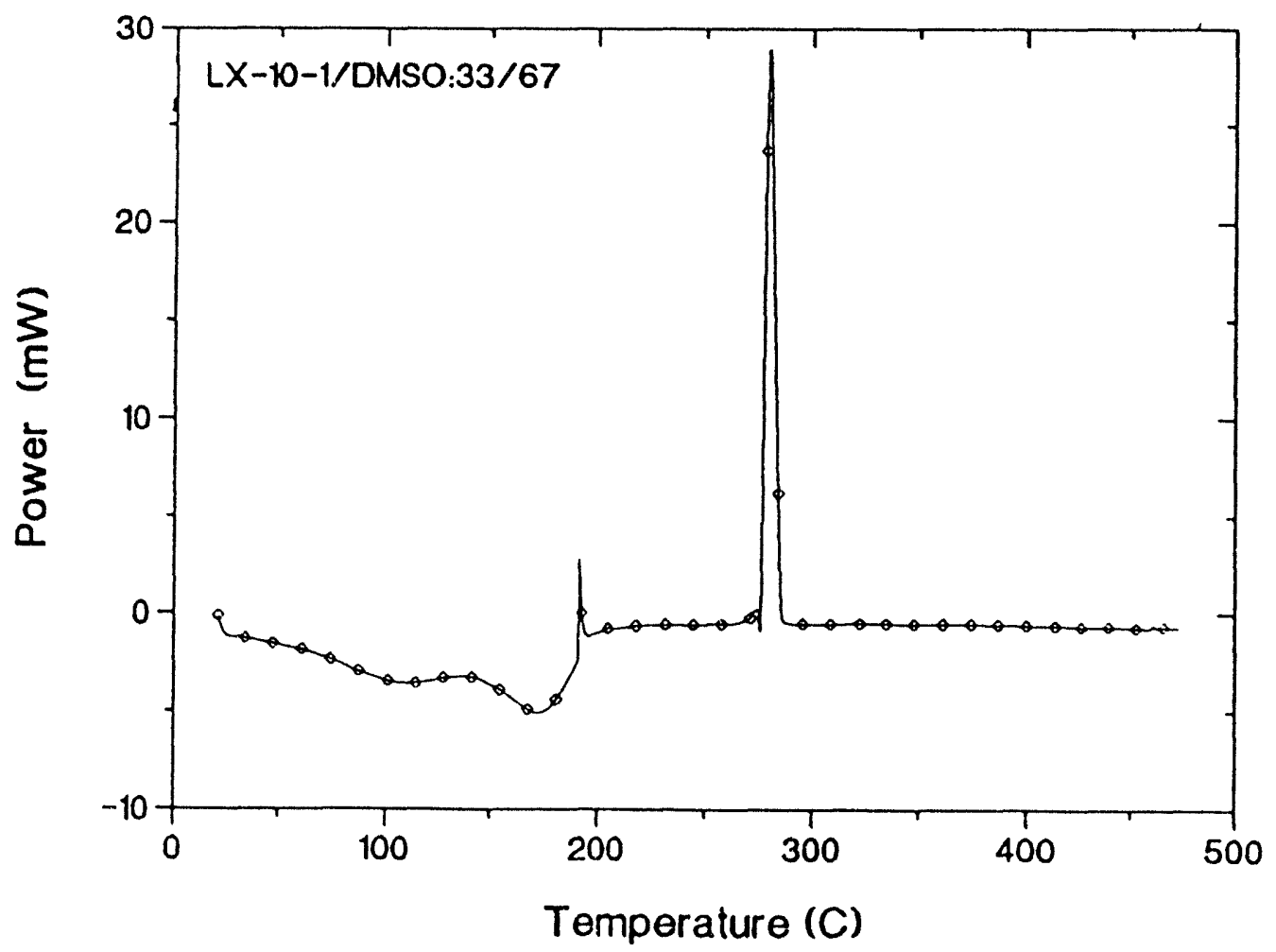

Figure 4. DSC trace of 33/67:LX-10-1/DMSO is similar to Figure 3. 


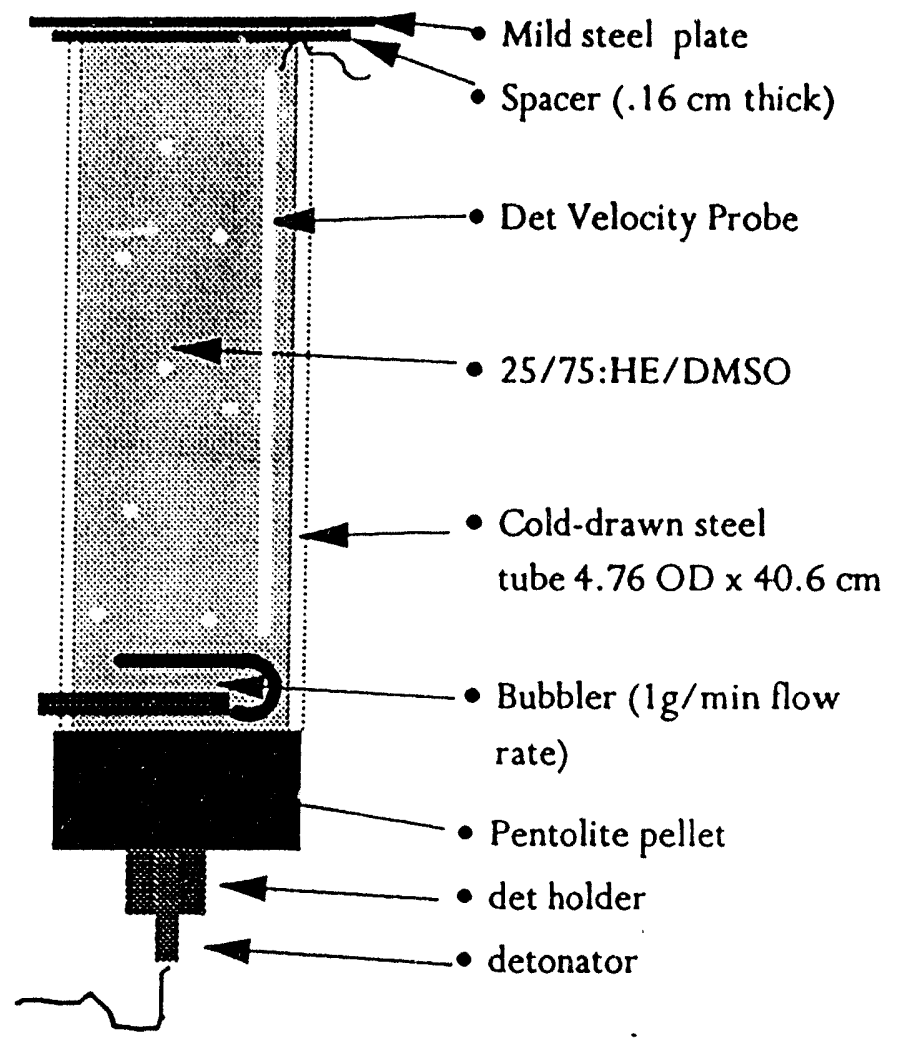

Figure 5. Schematic of Cardless Gap Test for liquids. 

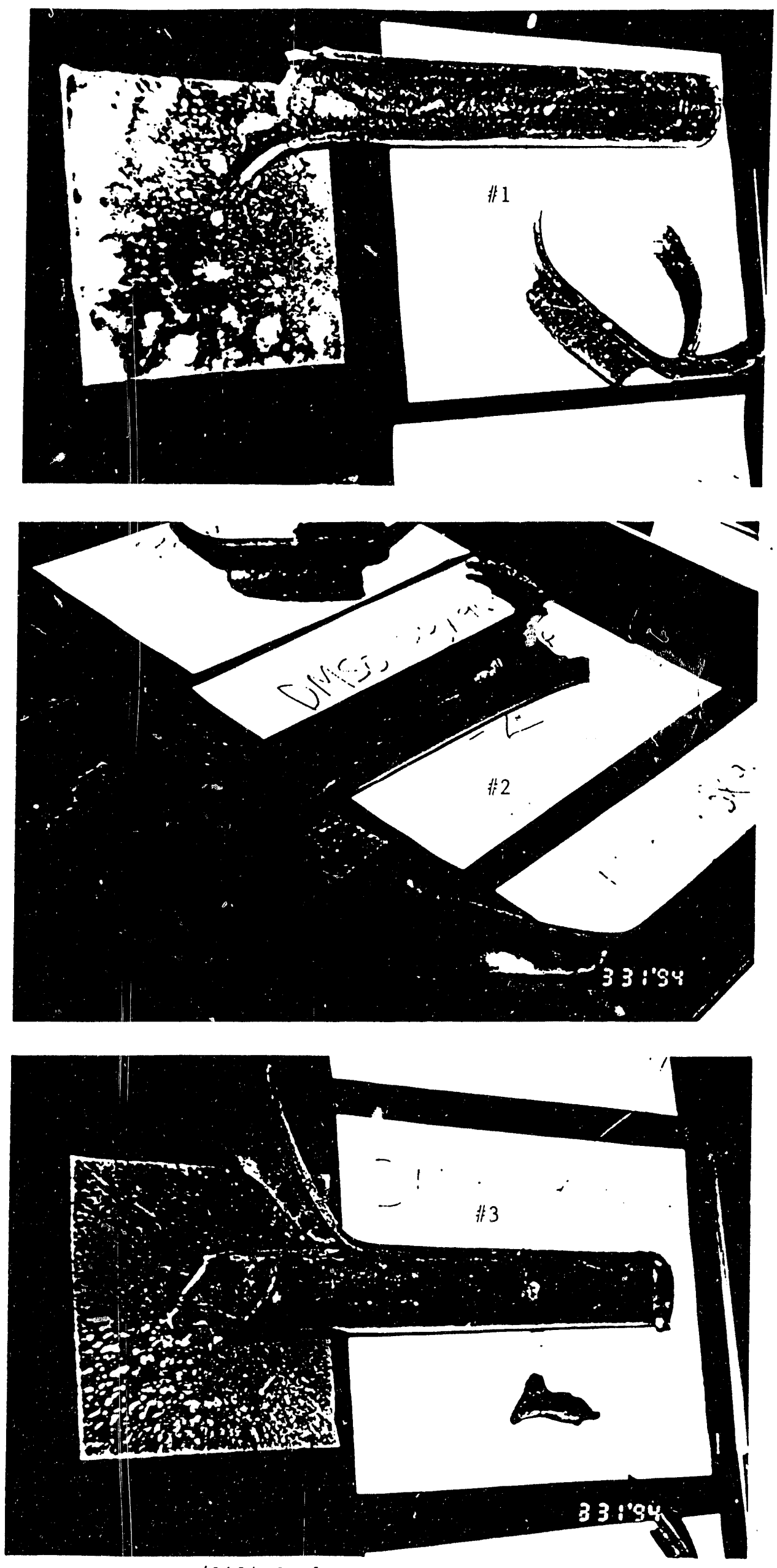

Figure 6. DMEJ/9404 Carless gap tests. 

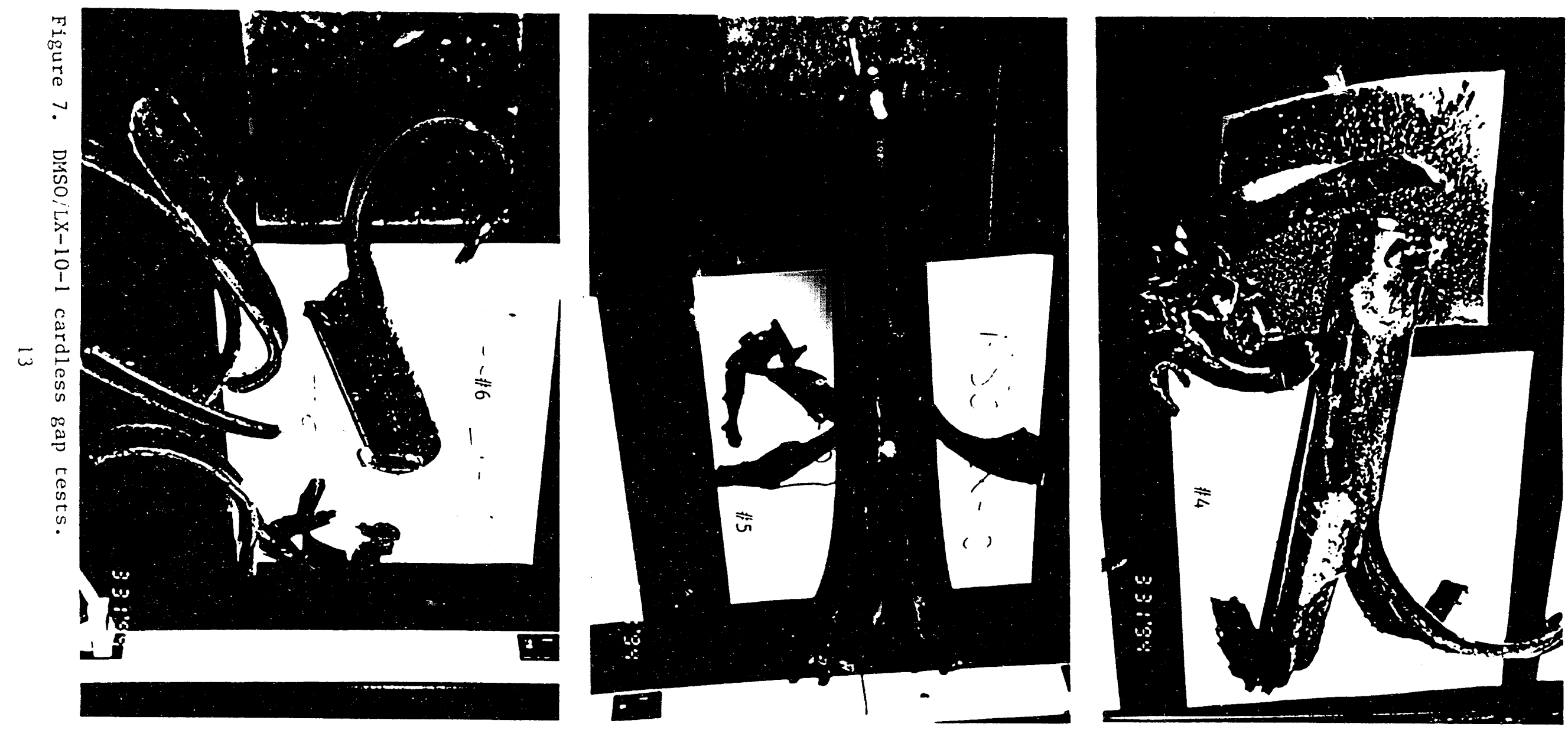


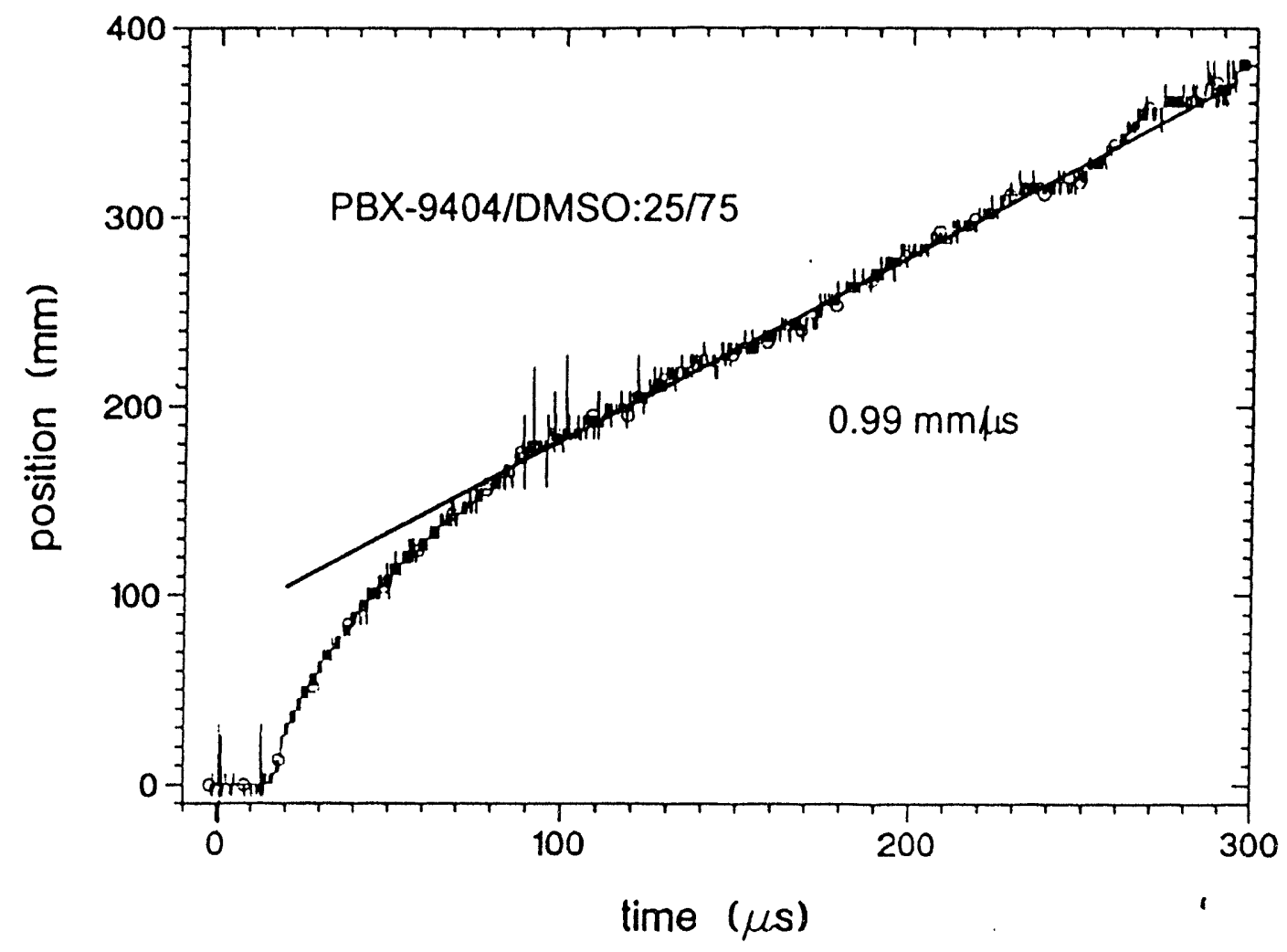

Figure 8. Velocity probe record for cardless gap test \#1 (PBX-9404) gave $0.99 \mathrm{~mm} / \mu \mathrm{s}$

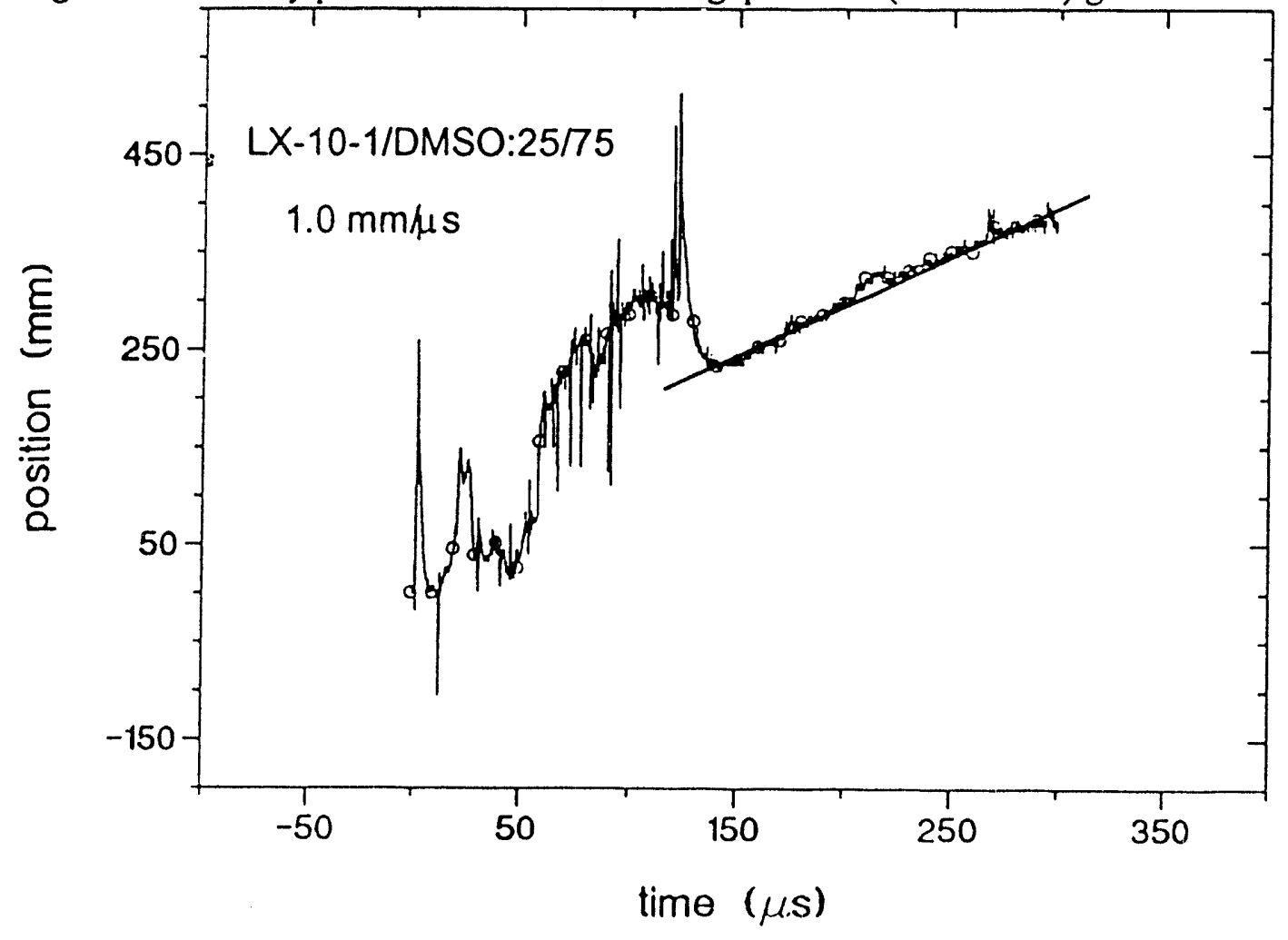

Figure 9. Velocity probe record for test $\# 5$ (LX-10-1) gave $0.99 \mathrm{~mm} / \mu \mathrm{s}$ 


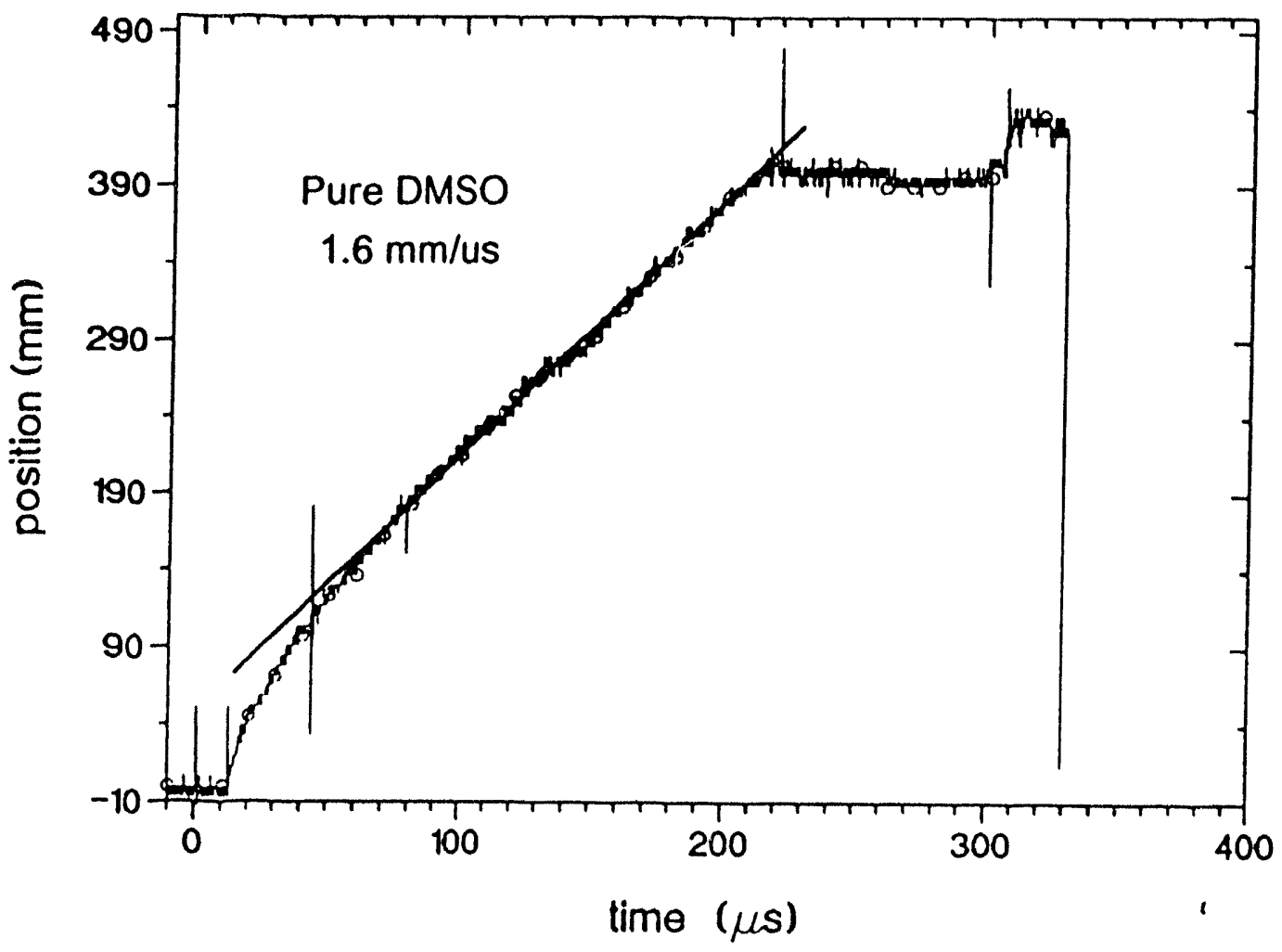

Figure 10. Velocity probe record for test \#13 (DMSO) gave $1.6 \mathrm{~mm} / \mu \mathrm{s}$. 

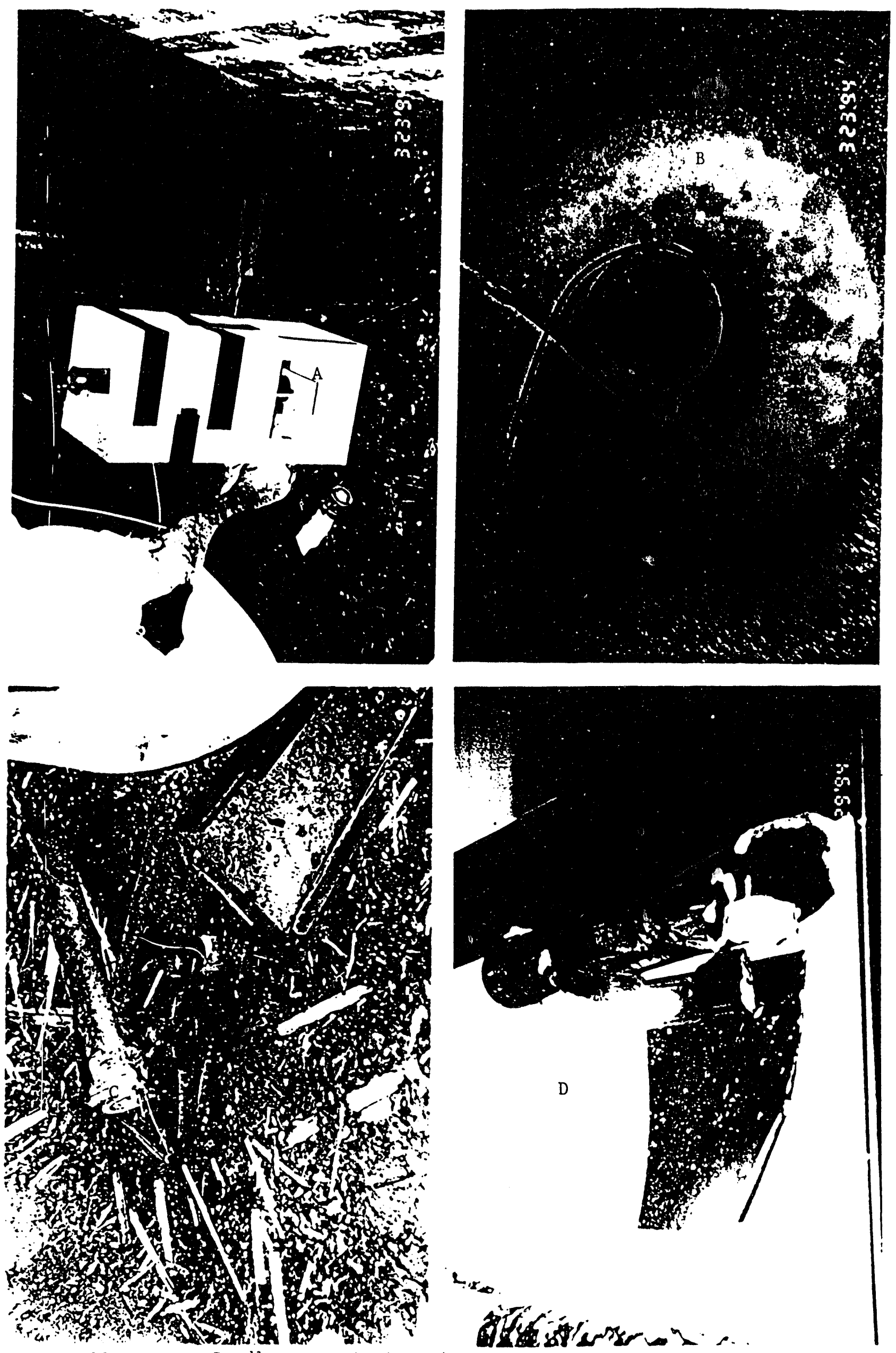

Eigure 11. Frozen Cardless gap tests setup. 

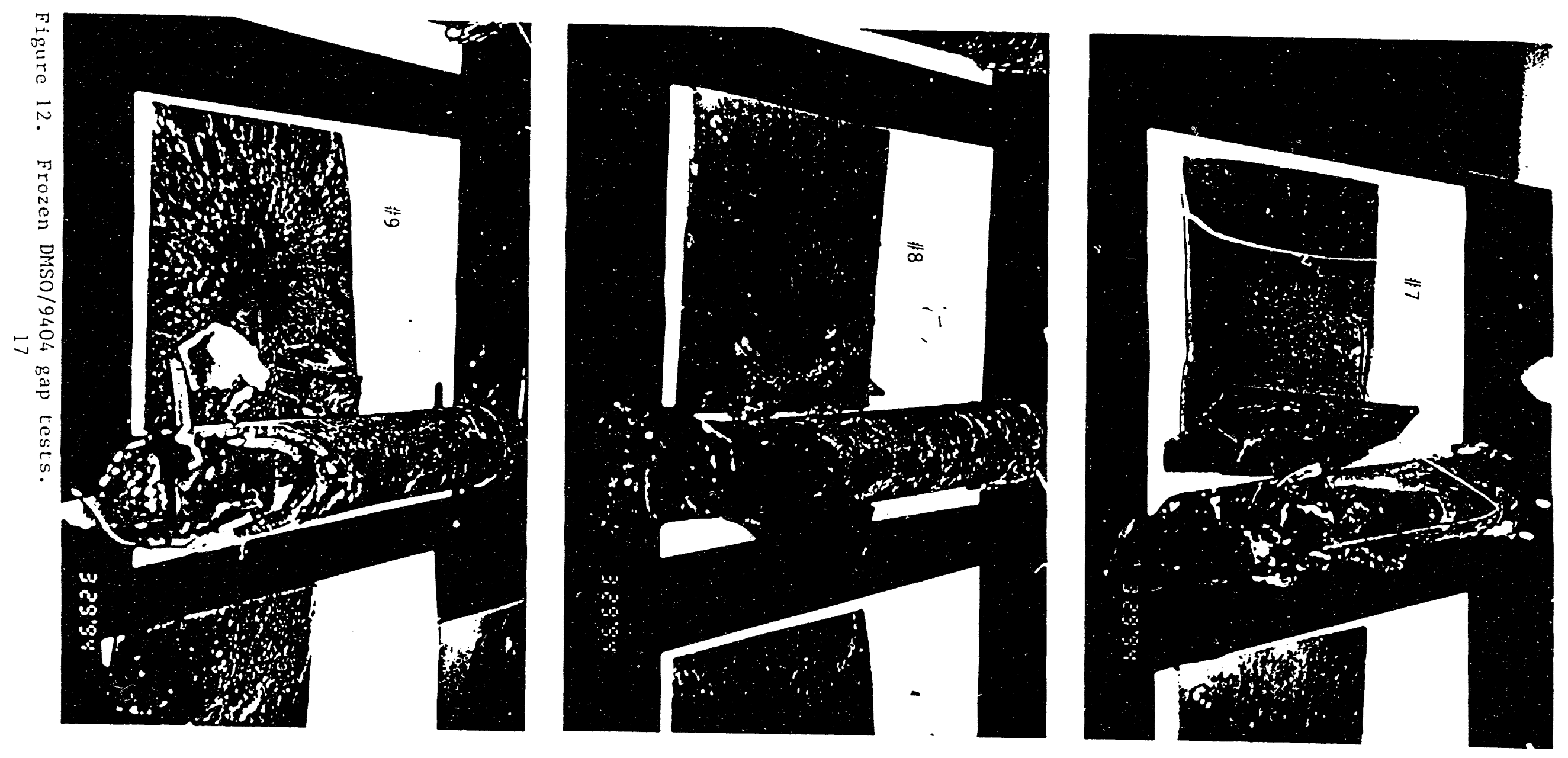

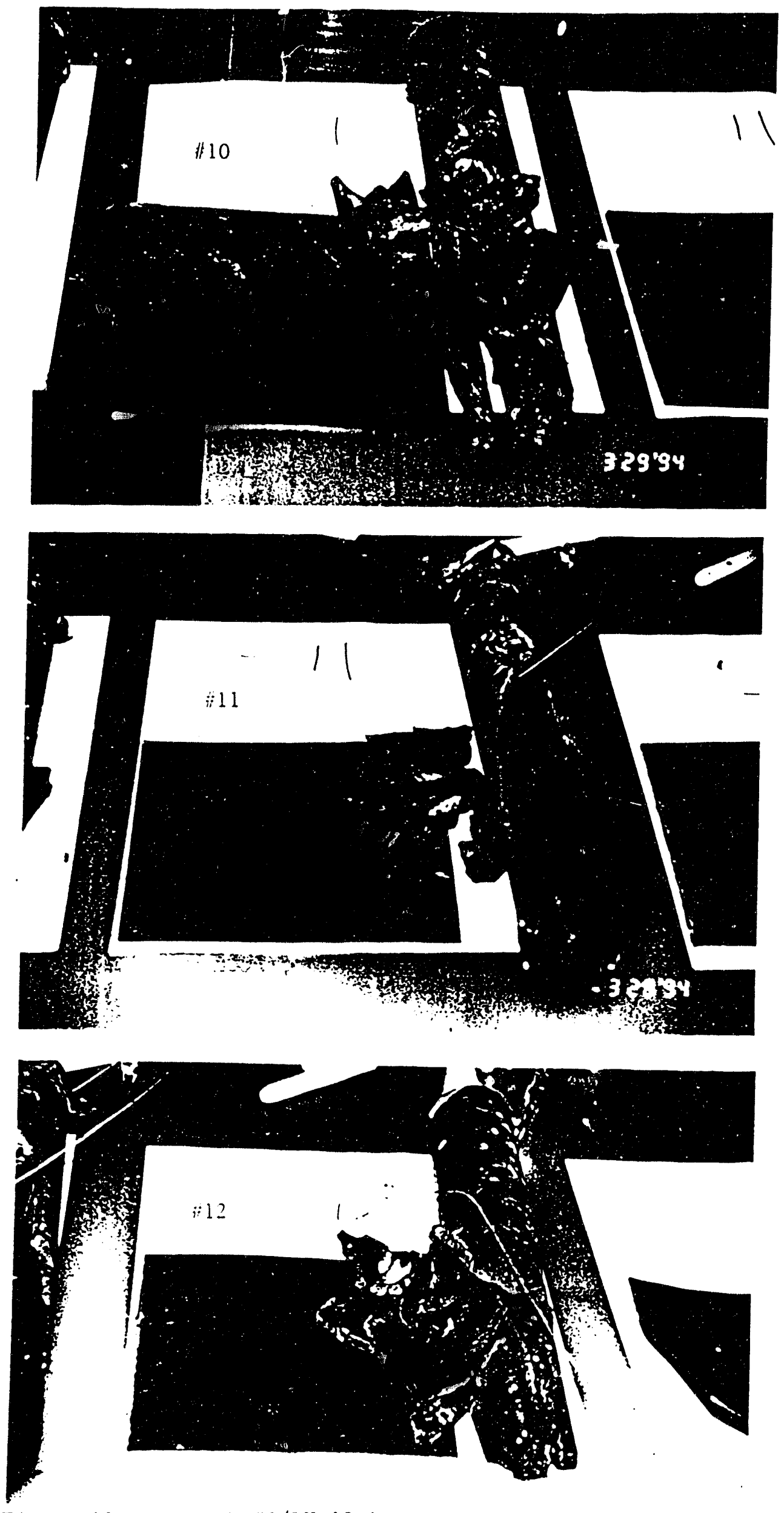

Figure 13. Frozen DMSO/LX-19-1 gap tests. 


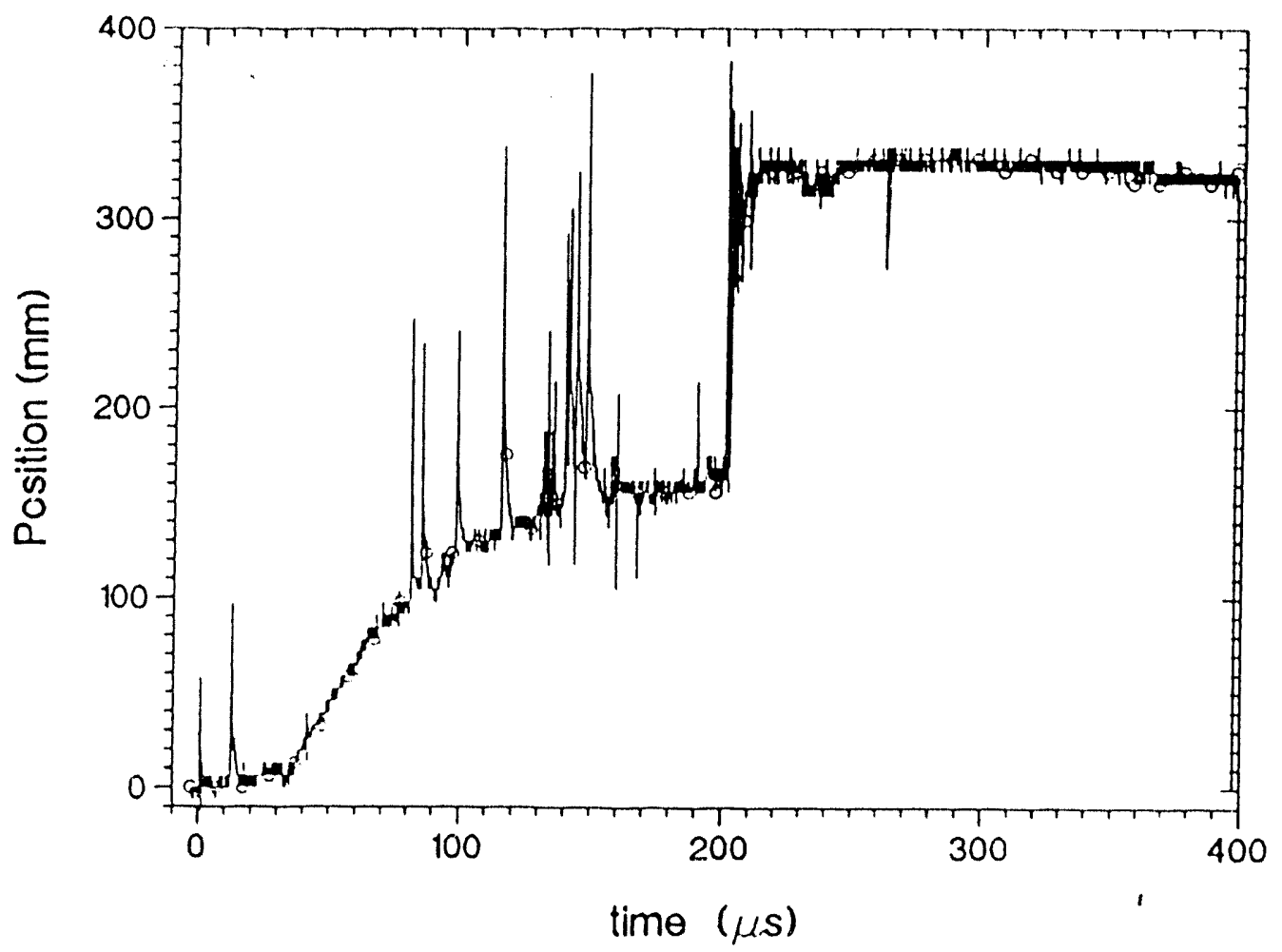

Figure 14. Velocity probe results from cardless gap test \#7 (Frozen DMSO/9404).

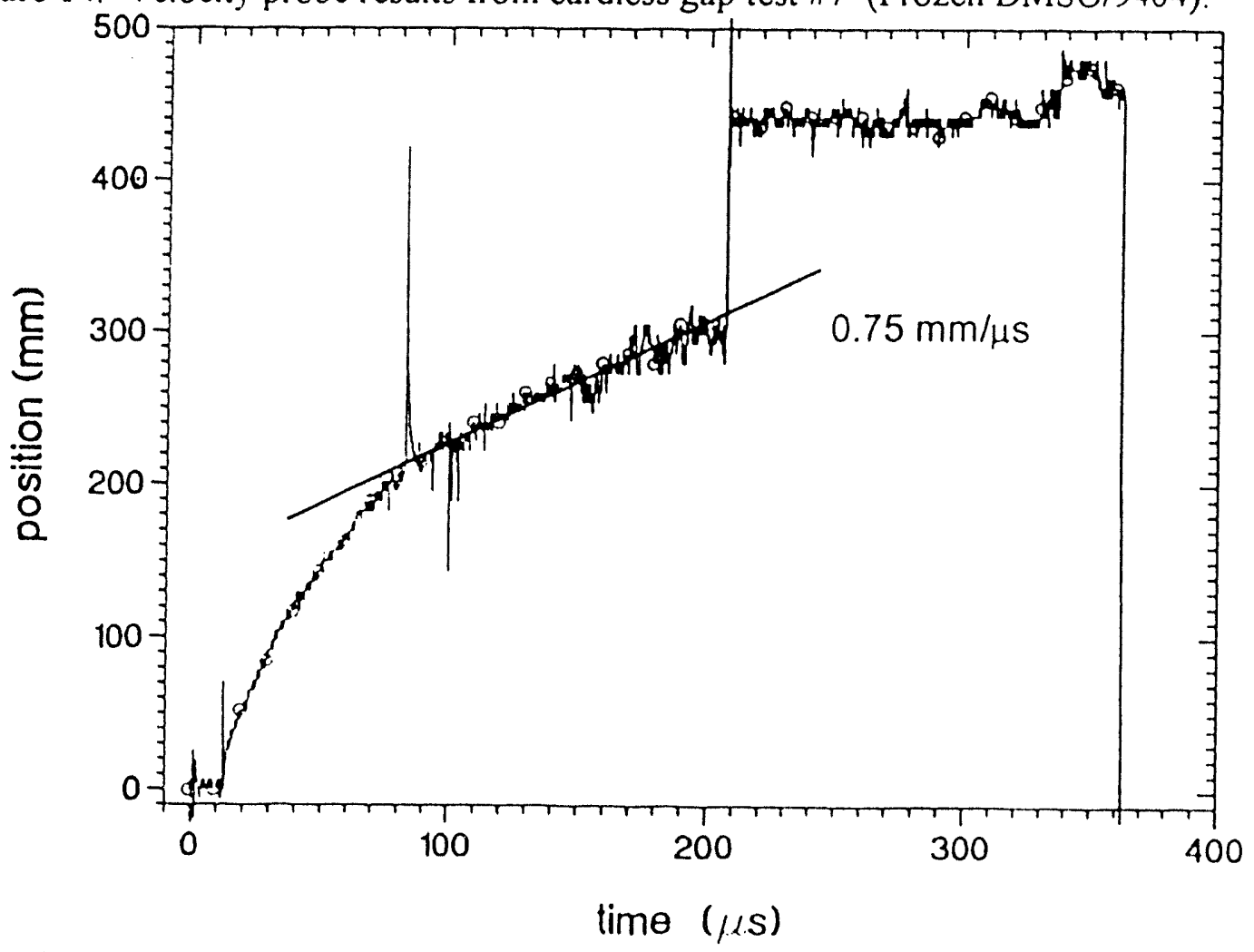

Figure 15 Velocity probe results from cardless gap test \#11 (DMSO/LX-10-1). 
Appendix A - Peer Review No. 891

"Detonability Tests on DMSO/LX-10 and DMSO/9404 Solutions 
PEER REVIEW

HEAF OPERATIONS

(Valid for 180 days after authorization)

Reference: B-191 FSP. Section 5.1.2.12.1

Till PERFORM DETONAOLLTY TESTS PECRREVICW NO. 991

ON DMSO/LX-10 ANO DMSO/94045OLUTIONS PeCrReviewNo.

Requester HELM Accoun No. $07 / 7-5 /$ Date 2/15/94 Lab/Facility (Room No.) IKG TANK_Explosives Weight $132 \mathrm{~g}$ PENTOLTE BOosTER

Material Safety Data: Explosive PENTOLITE

Composition (SEE ATTACHED NFORMATION) PENOLITEL 50 W\% PETN

LLNL Type I / D Storage Group___ Storage Review Date

$\mathrm{DH} 50 \_35 \mathrm{~cm}$ DTA Exo_ CRT_ Spark

Compatibility 1

DMSO CAN CARRY CONTAMINANTS
Any TOXicity THROUGH THE SKIN. Other

Disposal Method BURN AT SITE 300

Fill in suitable information in spaces above. Briefly describe the experiment, operation or test below or on extra pages. Note special hazards with precautions or remedies and remorc operations.

Job Description: (Add additional pages if necessary)

- SEE ATtACHED INFORMATION

Approval by PR Committee:

- Group I Mayk offomer 3/4/9y Group IV2

Group ${ }^{3}{ }^{3}$ Group $V^{4}$

Group III Ehelef fagora $3 / 4 / 94$

Operator Review 5

Facility Management6

1. Incluie names and acceprabilities of adhesives planned for use

2. Synthesis operations only'.

3. Group 11 required to verify firing load limit calculations.

4. Direcied Energy Experiments only.

5. As required by B-191 FSP. Section 5.1.2.12.1.

6. As required by B-191 FSP. Section 5.1.2.12.1. EMS Leader or Operations Supervisor are alierrates to Facility Manager.

HEAF Pe: Revicw for Opcrauons HEAF 92.010 Rev. 2 Page 2


Peer Revie:v 891

DMSO/EXPLOSIVE DETONABILITY TESTS

This peer review concerns the detonability testing of two solutions of explosive in DMSO. The information obtained in the tests will be used to obtain shipping classifications.

\section{SOLUTION 1}

25 wt. $\%$ LX-10-1 ir. DMSO

$\begin{array}{ll}\text { DH50 } & >177 \mathrm{~cm} \\ \text { DSC } & \text { onset of exotherm }-250 \mathrm{C} \\ \text { CRT } & 0.04 \mathrm{cC} / 25 \mathrm{~g} \text { @ } 120 \mathrm{C} \text { for } 22 \text { hours } \\ \text { Spark } & \text { not sensitive }\end{array}$

SOLUTION 2

25 wt. $\%$ PBX9404 in DMSO

$\begin{array}{ll}\text { DH5O } & >177 \mathrm{~cm} \\ \text { DSC } & \text { onset of exotherm - } 180 \mathrm{C} \\ \text { CRT } & 0.36 \mathrm{cC} / 25 \mathrm{~g} \text { e } 220 \mathrm{C} \text { for } 22 \text { hours } \\ \text { Spark } & \text { not sensitive }\end{array}$

A gap test for liquids will used to determine the detonability of these solutions. A document describing the test is attached. A total of twelve tests will be conducted - three of each solution at a temperature of approximately $20 \mathrm{C}$ and three of each below tine freezing points of the solutions. DMSO/PBX9404 freezes at $-11 \mathrm{C}$ and DMSO/LX-10 at $+3 \mathrm{C}$.

The weight of explosive in each test will be approximately $130 \mathrm{~g}$ of $\mathrm{HE}$ in solution and $170 \mathrm{~g}$ of Pentolite in the bocster for a total of $300 \mathrm{~g}$.

\section{TANK PROTECTION}

The shot will be placed inside a heavy walled steel cylinder with a steel plate top and bottom to protect the tank from shrapnel damage. 


\section{DMSO/HE SOLUTION CONTAINMENT}

The first shot will be set up as a complete gap test, but with only a sheet of polyethylene taped into the bottom of the tank to collect the solution if it is splattered around the tank. Full protective equipment will be worn by the operator when the tank is inspected after the shot. Contact with the skin must be avoided to prevent DMSO from carrying $\mathrm{HE}$ and other contaminants through the skin.

If the solution does not detonate, it may be ignited by the fireball from the rooster as it is sprayed into the tank. If this happens no cleanup of the tank may be necessary before the next shot. If the solution collects on the plastic sheet, cellulose spill collectors may be used to absorb the liquid. place the contaminated spill collectors in appropriate containers and send to Site 300 for burning in the $\mathrm{HE}$ burn pit or "iron horse". In subsequent shots place either wood chips or the spill collector on the plastic sheet before the shot to help absorb liquid immediately after the shot.

\section{AIR SUPPLY FOR BUBBLER}

These shots require an air supply in the tank to inject bubbles into test solution. A special flange has been built for these tests and will be fitted with a check valve on the tank side of the flange. The check valve will prevent back flow of tank gases into the air supply line.

\section{CONTINUOUS DETONATION VELOCITY PROBE}

A velocity probe is used in these shots. It is described in an attached document. One RG58 cable with a BNC connector is required to power the probe. The power supply for the probe is located outside the tank, and another cable is required to connect the power supply to the control room scope. After the tank door has been secured for the shot, the power supply for the probe may be turned on and remain on until the shot has been fired.

\section{TIMING REQUIREMENT}

The digital Tektronix scope will record a voltage signal from the velocity probe. It will be triggered by the det pulse. 
This page must $b c$ completed and saved with the Peer Review records. In the interest of saving space, this page may be separated from the preceding pages which contain no recorded data.

Shot ID

Special Case $(\leq 100$. grams)

Group II Review

Signature

Table 1

HE Weight for the Impulse Load Limit

\begin{tabular}{|c|c|c|c|}
\hline HE Type & $\begin{array}{l}\text { Amount in Shot } \\
\text { (gms) }\end{array}$ & $\begin{array}{l}\text { Maximum Amount Allowed } \\
\text { (gms) }\end{array}$ & Mass Fraction \\
\hline HMX & $130+86$ & 800 & 0.27 \\
\hline TNT & 86 & 1000 & 0.09 \\
\hline TATB & & 900 & \\
\hline Total in Shot & & Total Mass Fraction & 0.36 \\
\hline
\end{tabular}

Table 2

Static Pressure, Immediate Burn Load Limits

\begin{tabular}{|c|c|c|c|}
\hline$\stackrel{A}{\text { Material }}$ & $\begin{array}{c}\text { B } \\
\begin{array}{c}\text { Heat of Combustion } \\
(\mathrm{kcal} / \mathrm{gm})\end{array}\end{array}$ & $\begin{array}{c}\mathrm{C} \\
\text { Amount } \\
\text { (gms) }\end{array}$ & $\begin{array}{c}\mathrm{D} \\
\mathrm{B}^{*} \mathrm{C} \\
(\mathrm{kcal})\end{array}$ \\
\hline Plywood & 4.2 & & 1 \\
\hline Metal Powder & 7.4 & & \\
\hline Plastic; Foam & 11.0 & & \\
\hline HMX & 2.3 & $130+86$ & 497 \\
\hline TATB & 2.8 & & \\
\hline TNT & 3.5 & 86 & 301 \\
\hline $\begin{array}{l}\text { All hydrocarbons DMSO } \\
\text { (i.e. kerosene, solyents) }\end{array}$ & $\frac{11.0}{6}$ & 391 & 2,346 \\
\hline $\begin{array}{l}\text { For reduced loads } \\
(390 . \mathrm{kcal})\end{array}$ & $\begin{array}{l}\text { For full loads } \\
\text { (2730. kcal) }\end{array}$ & $\begin{array}{l}\text { TOTAL ENERGY } \\
=\sum \mathrm{B}^{*} \mathrm{C}(\mathrm{kcal})\end{array}$ & 3,144 \\
\hline
\end{tabular}

Table 3

Secondary Burn Load Limits

\begin{tabular}{|l|c|c|c|}
\hline Material Type & $\begin{array}{c}\text { Maximum Allowed } \\
\text { Weight } \\
\text { (Lbs.) }\end{array}$ & $\begin{array}{c}\text { Maximum Weight } \\
\text { Present } \\
\text { (Lbs.) }\end{array}$ & $\begin{array}{c}\text { Mass } \\
\text { Fraction }\end{array}$ \\
\hline $\begin{array}{l}\text { Cellulose } \\
\text { wood, plywood. } \\
\text { cardboard, papes. } \\
\text { masonitc, paricle board }\end{array}$ & 8. & 2.8 & 0.35 \\
\hline $\begin{array}{l}\text { Plastics } \\
\text { foams (any density). } \\
\text { fibercomposite material }\end{array}$ & 1.7 & & \\
\hline
\end{tabular}




\section{a. SAPTEST-CTest1(a) (iii)}

\section{(1) Introduction}

This test is designed to determine whether a liquid or solid substance will maintain a stable detonation and, if it does, measure its shock sensitivity. The sample is loaded in a steel tube of specific dimensions and is subjected to the shock wave generated by the detonation of a pentolite

\section{(2) Apparatus and Materials}

(a) Solids. The apparcius for the Gap Test for solids is shown in Figure 5 2 The test sample is contained in a seamless carbon steel cylinder. Spacers are used to separate a mild steel witness plate from the sample tubing at the upper end. The bottom of the cylinder is closed with two layers of polyethylene sheets held in place with gum rubber bands and palyrinylch oride electrical insulating tape. There is no other gap between the pentolite booster and the test sampde. A continuous velocity of detoration ${ }^{1}$ probe made of thin aluminum tube with an axial resistance wire having a resistance of $3.0 \mathrm{ohms} / \mathrm{cm}(7.6$ ohms/in) is mounted on the wall of the sample tubing.

${ }^{1}$ Ribovich, J., Watson, R.W. and Gibson, F. C., Instrumented Card Gap Test, AIAA loumal Vol 6, No. 7. pp. 1260-1263, 1965

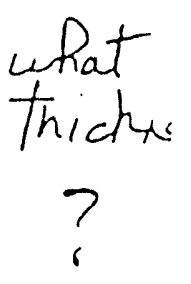

The outer tubing of the probe is crimped against the inner wire at the lower end forming a resistor. As a detonation wave moves up the tubing, the outer wall crushes against the inner wire, shortening the effective length and changing the resistance of the wire. If a constant current (usually 0.06 amperes) is made to flow between the outer and inner conductors, the voltage between them is proportional to the effective length and can be recorded as a function of time using an oscilloscope. The slope of the oscilloscope trace is thus proportional to the velocity of the shock wave.

(b) Liquids. The apparatus for the Gap Test for liquids is the sume as that for solids except that a method of injecting bubbles into the liquid sample is provided. The experimental set-up is given in Figure 5-3. The bubbles are injected by means of a $2.35 \mathrm{~cm}(0.925 \mathrm{in})$ diameter loop of vinyl plastic tubing of the type used for medical catheterization with an o.d. of 0.18 $\mathrm{cm}(0.071 \mathrm{in})$ and a wall thickness of $0.04 \mathrm{~cm}$ $(0.02$ in) located at the bottom of the sample This loop is perforated with two rows of holes diametrically opposite to each other with the holes in each row spaced $0.32 \mathrm{~cm}$ $(1 / 8$ in) apart. The holes are made by inserting a $0.13 \mathrm{~cm}(0.051 \mathrm{in})$ diameter needle through the wall of the tubing. Because of the elastic nature of the tubing the holes contract almost completely when the needle is withdrawn, so the actual hole diameter is much smaller than $0.1 \mathrm{~cm}(0.04$ in). The tubing is sealed at one end of the loop with epoxy' cement and a length of the tubing from the other end of the loop is led outside to the air supply through a hole in ? the steel tubing, which is sealed with epoxy cement. Air is supplied at a pressure of 30 to 100 kilopascals (4.4 psi to $14.5 \mathrm{psi}$ ) to obtain a flow rate of 12 liters/minute $(0.32$ gal/min). Where it is suspected that the sample may react with the steel tube, the inside of the tube is sprayed with a nuorocarbon resin coating. 


\section{(3) Prosedure}

The sample is loaded to the top of the steel tube. For liquid samples, adequate ullage should be allowed. Solid samples are loaded to the density attained by tapping the cylinder until further settling becomes imperceptible. The sample is tested at ambient conditions $\left(25 \pm 2^{\circ} \mathrm{C}\right)$ and is subjected to the shock wave generated by the detonation of a Pentolite (50/50 PEIN/TNT) pellet. The Pentolite pellet is in intimate contact with the bottom of the test sample and initiated with a standard No. 8 detonator shown in Figure 5-4. The oetonator is held in place by a cork detonator holder. Three tests should be performed on each sample.

(4) Criteria and Method of

\section{Assessing Results}

The criteria for propagation are:

(a) A stable propagation velocity greater than the velocity' of sound in the substance;

the witness plate;

(b) A hole is punched through

(d) The sample tube is fragmented along its entire length.

The overall test results are considered positive ( $t$ ) if any two of the three criteria listed above are met. 
Mild Steel Witness

Plate (ASTM 1020-1025)

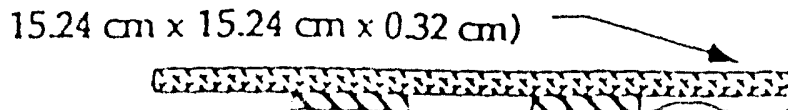

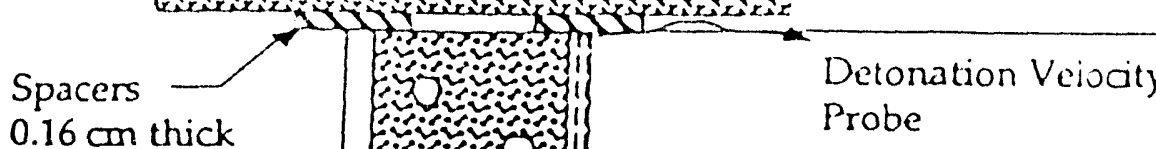

Cold-Drawn Seamless

Steel Tubing

ASTM(1020-1025)

$4.76 \mathrm{~cm} \mathrm{OD} 1.875$ of

$3.65 \mathrm{~cm} \mathrm{ID}$

$$
\frac{1.437}{.433 / 2}=.219
$$

Liquid Sample

10
10
$2=.219$

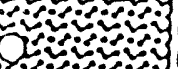

Probe

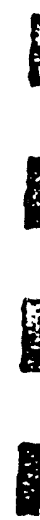

圆

s

To Air Supply

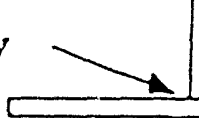

Bubbler

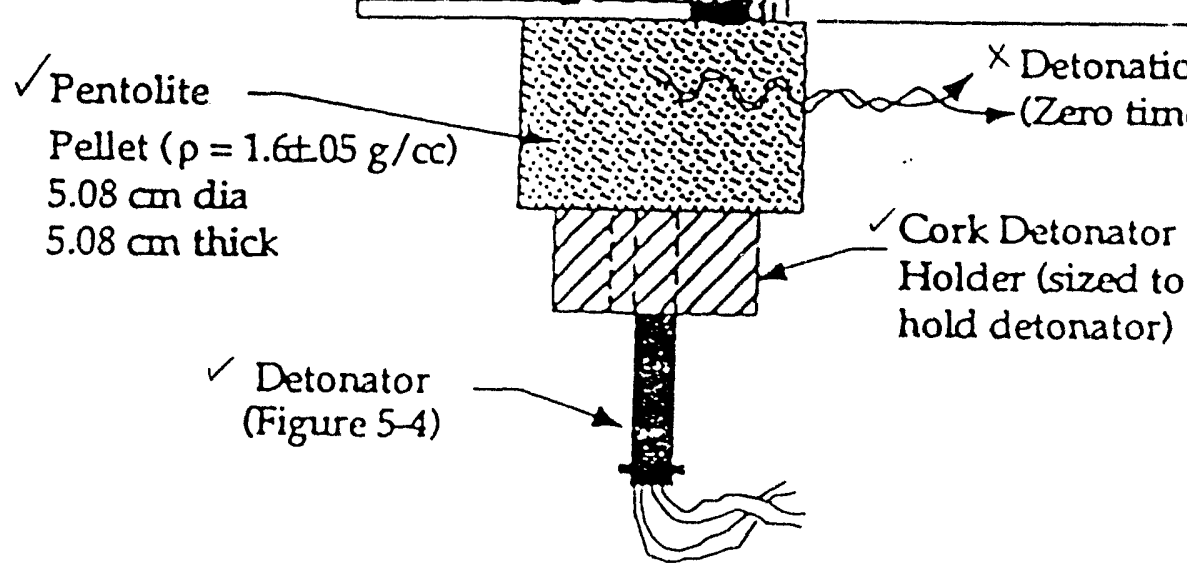

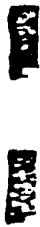

FIGURE 5-3. GAP TEST CONFIGURATION FOR LIQUTD SUBSTANCES - Test 1(a) (iii) 

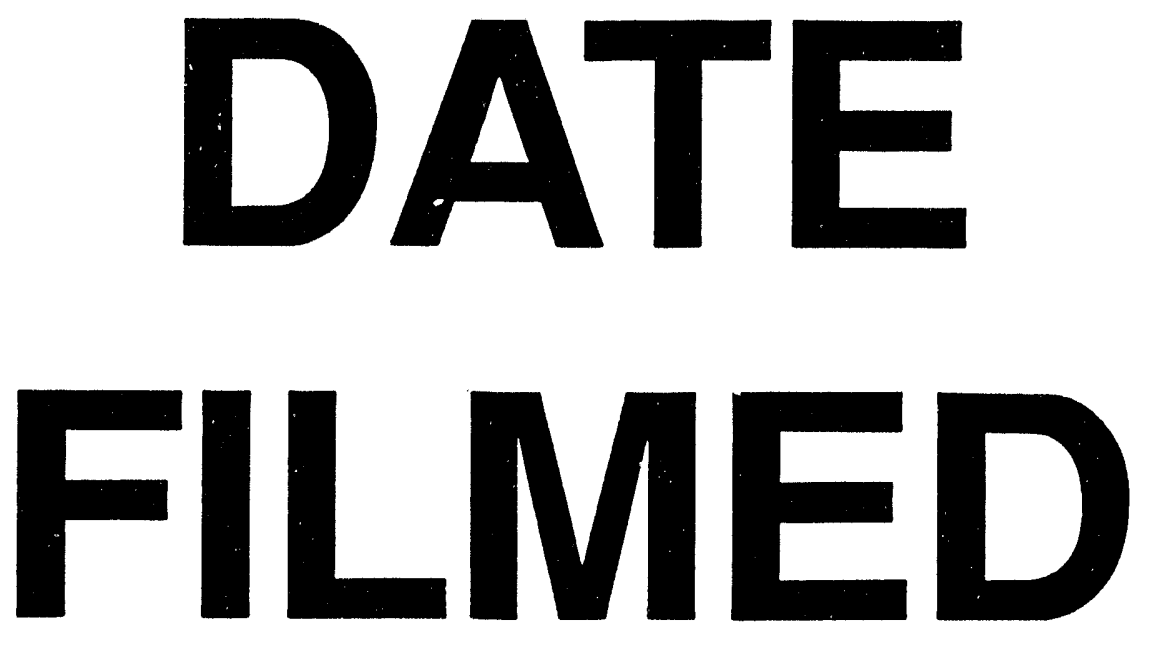

$9 / 13 / 94$
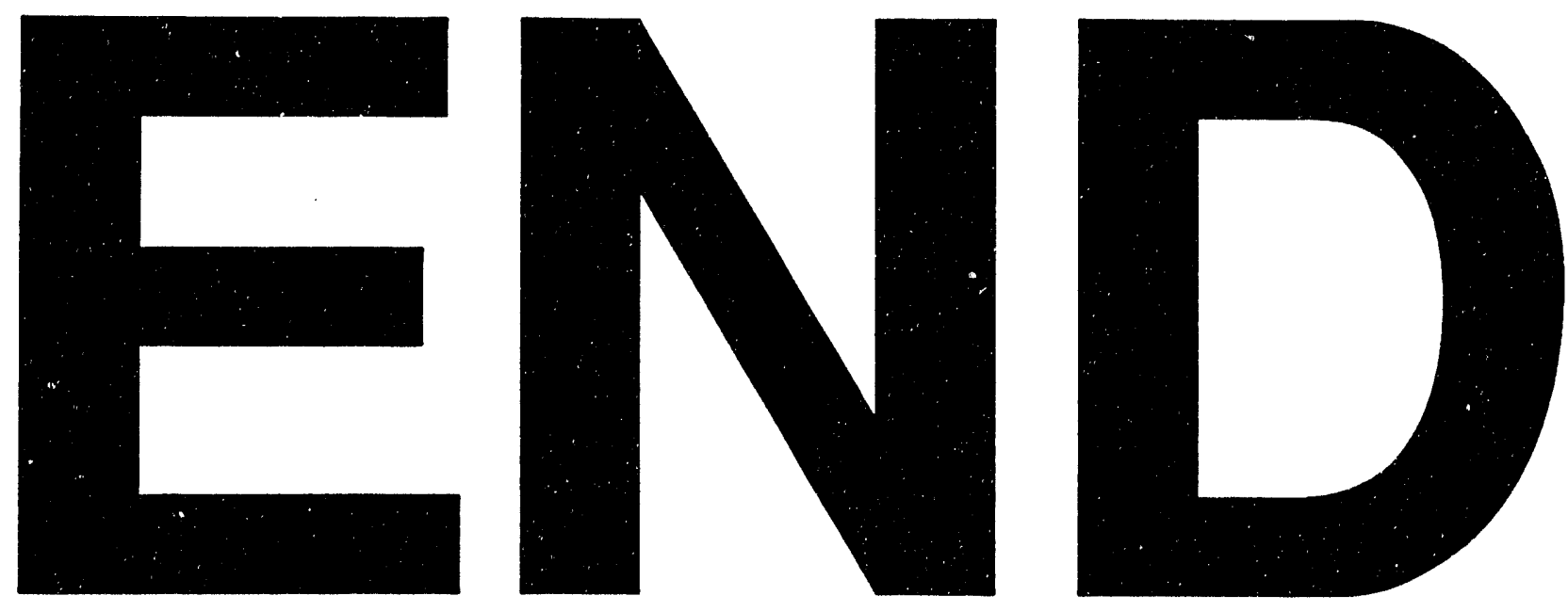


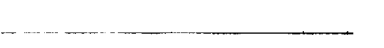

